\title{
Tritiated water vapor in the stratosphere: Vertical profiles and residence time
}

\author{
D. H. Ehhalt and F. Rohrer \\ Forschungszentrum Jülich, Institut II: Troposphäre, Jülich, Germany
}

S. Schauffler and W. Pollock

National Center for Atmospheric Research, Boulder, Colorado, USA

Received 1 October 2001; revised 25 February 2002; accepted 27 February 2002; published 19 December 2002.

[1] The historic and partly unpublished measurements of the tritium content in stratospheric water vapor made at the National Center for Atmospheric Research between 1975 and 1983 are reanalyzed. The resulting vertical profiles of the T content, mainly at $32^{\circ} \mathrm{N}$ latitude, show little variation with altitude above $20 \mathrm{~km}$ but a strong decay with time. This decay is a consequence of the large $\mathrm{T}$ injections into the stratosphere by the atmospheric tests of high-yield thermonuclear devices prior to 1963 and seems to proceed with a single e-fold time of 5.12 years. Correcting for the radioactive decay of HTO within the stratosphere and for a temporal increase in stratospheric $\mathrm{H}_{2} \mathrm{O}$, we obtain a decay time for stratospheric HTO of $7.7 \pm 2.0$ years. This decay time, which is solely due to the transport of HTO into the troposphere, is much longer than the age of stratospheric air at these altitudes or the accepted values for stratospheric residence times. The differences are discussed and resolved by interpreting the HTO decay time as the Eigentime of the longest-lived mode of the stratospheric transport equations. This Eigentime should provide a useful constraint in modeling stratospheric transport. INDEX TERMS: 0341 Atmospheric Composition and Structure: Middle atmosphere - constituent transport and chemistry (3334); 3334

Meteorology and Atmospheric Dynamics: Middle atmosphere dynamics (0341, 0342); 3362 Meteorology and Atmospheric Dynamics: Stratosphere/troposphere interactions; KEYWORDS: tritiated water vapor, stratosphere, residence time, Eigenfunctions of the vertical diffusion operator

Citation: Ehhalt, D. H., F. Rohrer, S. Schauffler, and W. Pollock, Tritiated water vapor in the stratosphere: Vertical profiles and residence time, J. Geophys. Res., 107(D24), 4757, doi:10.1029/2001JD001343, 2002.

\section{Introduction}

[2] Stratospheric water vapor contains minute amounts of tritium, $\mathrm{T}$, the radioactive isotope of hydrogen with a (radioactive) decay time of 17.8 years. This $\mathrm{T}$ content is usually expressed in tritium units, TU, where 1 TU corresponds to a $\mathrm{T} / \mathrm{H}$ ratio of $10^{-18}$. Today most of the $\mathrm{T}$ present in the stratosphere as tritiated water vapor, HTO, is produced naturally by cosmic radiation acting upon the atoms present in the atmosphere. This natural atmospheric production rate is small, $0.28 \mathrm{~T}$ atoms $\mathrm{cm}^{-2} \mathrm{~s}^{-1}$ averaged over a solar cycle; moreover, only half of that production takes place in the stratosphere [Craig and Lal, 1961; Lal and Peters, 1962; Masarik and Beer, 1999]. It gives rise to a more or less steady-state background $\mathrm{T}$ content in stratospheric water vapor which averages $\sim 5 \times 10^{5} \mathrm{TU}$, an estimate which assumes an average tropopause height of $12 \mathrm{~km}$, an average mixing ratio of $5 \mathrm{ppmv}$, and a residence time of 5 years for stratospheric water vapor.

[3] In the past, however, large amounts of T were injected into the stratosphere by atmospheric thermonuclear test explosions [cf. Eriksson, 1965]. Notably, the high-yield

Copyright 2002 by the American Geophysical Union. 0148-0227/02/2001JD001343
Russian tests in the early 1960s increased the stratospheric burden of $\mathrm{T}$ by at least 2 orders of magnitude above the natural background. During the subsequent moratorium, virtually no thermonuclear $\mathrm{T}$ was added to the stratosphere, and the later Chinese test explosions introduced $\mathrm{T}$ essentially into the lower stratosphere (below $20 \mathrm{~km}$ altitude). Thus one can hope to observe the decay of the large burden of HTO injected into the middle and upper stratosphere prior to 1963 unperturbed by later nuclear events and, choosing the right period of time, unperturbed by the cosmogenic production of $\mathrm{T}$ as well.

[4] The decrease in the $T$ content of stratospheric water vapor is dominated by the transport of HTO into the troposphere. There it is rapidly diluted by $\mathrm{H}_{2} \mathrm{O}$, owing to the large amount and rapid cycling of tropospheric water vapor. As a consequence, the $\mathrm{T}$ content of tropospheric water vapor is several orders of magnitude lower than that of stratospheric $\mathrm{H}_{2} \mathrm{O}$. Because of the low $\mathrm{T}$ content of tropospheric $\mathrm{H}_{2} \mathrm{O}$, the reflux of HTO from the troposphere to the stratosphere is negligible. Eventually, HTO is mixed into the oceans and diluted to a very low T content. Thus the decay of the bomb-induced pulse in stratospheric HTO should lend itself well to the study of the residence time of water vapor in the middle and upper stratosphere. 
[5] A few observations are available for this purpose. Using a balloon-borne cryogenic sampler, Pollock et al. [1980] have measured vertical profiles of the mixing ratio, the deuterium content, and the $\mathrm{T}$ content of water vapor between the tropopause and $40 \mathrm{~km}$ altitude. Altogether 13 profiles, most of them over Palestine, Texas, were obtained between 1975 and 1983. Only the data for the years 19751978 have been published [Pollock et al., 1980]. However, the data for the subsequent years were well archived and were available for the present analysis.

[6] In addition, there are measurements of the HTO mixing ratio in the lower stratosphere. They were obtained during Project Airstream, which sampled the upper troposphere and lower stratosphere up to $20 \mathrm{~km}$ altitude between $0^{\circ} \mathrm{N}$ and $65^{\circ} \mathrm{N}$ latitude during about the same time period with about three aircraft campaigns per year [Mason, 1985; Östlund and Mason, 1979]. These data will be used to augment the balloon data in the lower stratosphere.

[7] In the following, we first present a reanalysis of the balloon data. This is required because the collected stratospheric water vapor was isotopically contaminated by water adsorbed on the inner surfaces of the sampling and transfer system. This effect has to be evaluated and corrected for. In addition, there was a change in the sampling procedure for the second, unpublished part of the balloon flights, which was so far not accounted for. The new correction procedure provides a simpler and more accurate way of obtaining the actual $\mathrm{T}$ content of stratospheric water vapor than the one used by Pollock et al. [1980]. From the corrected HTO data we derive vertical profiles and the decay time of the $\mathrm{T}$ content in stratospheric water vapor in the middle and upper stratosphere. This decay time is compared with the published data on the age of stratospheric air and modeled values of the stratospheric residence time. The differences are analyzed.

\section{Experiment}

[8] The samples of stratospheric water vapor used for the isotopic analysis were collected by a cryogenic whole air collector carried aloft by balloon. The various sampling systems flown consisted of 4,8 , or 16 stainless steel cylinders, $70 \mathrm{~cm}$ long and $3.8 \mathrm{~cm}$ in diameter, partially immersed in liquid neon. Each cylinder was connected to a common manifold by a bellows-sealed stainless steel highvacuum valve (Nupro SS-4H), which was driven by a motor. All inner surfaces were electropolished. The cylinders used in sampling the highest altitudes and therefore requiring faster volume flow rates were equipped with a larger valve (Nupro SS-8TW-SW). An extra tube served as cryopump to pump on the inlet line and manifold during ascent and purge them between samples with ambient air. The partially flexible inlet line extended from the manifold to $6 \mathrm{~m}$ below the gondola. The gondola was suspended $75 \mathrm{~m}$ (in the earlier flights, $150 \mathrm{~m}$ ) below the balloon. This, together with sample collection during descent, minimized contamination exhaled by payload and balloon. The descent rate was $\sim 50$ $\mathrm{m} \mathrm{s}^{-1}$. The air samples, on the order of $10 \mathrm{~L} \mathrm{STP,} \mathrm{were}$ collected by opening and closing the motor-driven valves through telecommand from the ground. Because of the longer times required to collect $10 \mathrm{~L} \mathrm{STP}$ at higher altitudes ( $\sim 20 \mathrm{~min}$ at $35 \mathrm{~km}$ altitude), the balloon descent rate was slowed down during collection at those altitudes. In this way a height resolution of better than $0.5 \mathrm{~km}$ could be maintained over the profile. Further details of the cryogenic whole air sampler and its operation for the measurement of stable trace gases, such as $\mathrm{CH}_{4}, \mathrm{H}_{2}, \mathrm{CO}, \mathrm{N}_{2} \mathrm{O}, \mathrm{CF}_{2} \mathrm{Cl}_{2}$, and $\mathrm{CFCl}_{3}$, have been published by Lueb et al. [1975].

[9] Subsequent modifications of the sampler to include the measurement of $\mathrm{H}_{2} \mathrm{O}$ and its isotopic composition have been described by Pollock et al. [1980]. These consisted of a modification of the inlet line, a preflight bake-out and conditioning procedure, and a postflight sample transfer procedure. They were designed to minimize the water adsorbed on the inner walls of the systems in contact with the sampled air and so to minimize the contamination of the water sampled by the isotopic signature of the wall water. At the same time they were designed to keep, as far as possible, the adsorbed water at a fixed, reproducible isotopic composition to facilitate an eventual correction for isotopic exchange with the sampled stratospheric water. The wall water T content was $\sim 0 \mathrm{TU}$; its $\mathrm{D}$ content, $\delta(\mathrm{SMOW})$, was about $-140 \%$. The $\mathrm{D}$ content is given as a relative deviation of the $\mathrm{D} / \mathrm{H}$ ratio of the sample from that of a standard in units of per mil (\%o). The standard used is standard mean ocean water (SMOW).

[10] Despite all these efforts, contamination remained a serious problem. It required additional experiments to pinpoint the sources of contamination and to correct for their impact on the measured isotope contents. Pollock et al. [1980] describe the laboratory experiments needed to simulate the sample collection and recovery procedures, including the stages where the recovered water vapor was converted to $\mathrm{H}_{2}$, which was then metered and aliquotted for $\mathrm{D}$ and $\mathrm{T}$ analysis. The $\mathrm{D}$ content was measured with an Atlas M86 mass spectrometer. The T content was measured by a small proportional counter [cf. Scholz et al., 1970]. These experiments resulted in estimates of the amounts and isotope contents of the wall water adsorbed on the various parts of the system, except the inlet line whose wall water contribution was estimated from the change in the T content of the samples collected during the first part of a balloon flight. These experiments allowed derivation of correction factors to retrieve the actual stratospheric $\mathrm{H}_{2} \mathrm{O}$ mixing ratio and $\mathrm{T} / \mathrm{H}$ and $\mathrm{D} / \mathrm{H}$ ratios of the less contaminated samples. These correction factors were satisfactory for the $\mathrm{H}_{2} \mathrm{O}$ mixing ratio but much less so for the isotope ratios. The samples with high degrees of contamination were considered not corrigible. As a consequence, only the isotope data of the last of the published balloon flights, Fairbanks 30.4.1978, were accepted by the authors as reasonably reliable.

[11] In-flight air sample collection and the procedures for water recovery were modified for the flights since 1979, resulting in much larger air samples (see Figure 1). Unfortunately, these modifications were not accompanied by a simulation of the new sampling and recovery procedures with water vapor samples of known isotopic composition. Thus it is not clear whether the correction factors derived for the earlier flights are also applicable for the later ones. On the other hand, both data subsets should be treated in the same manner to ensure compatibility. Thus in this paper we devise a new approach to retrieve the true stratospheric $\mathrm{T}$ content from the one measured in the collected water samples. The current approach is less ambitious than the previous one [Pollock et al., 1980], which at the same time 

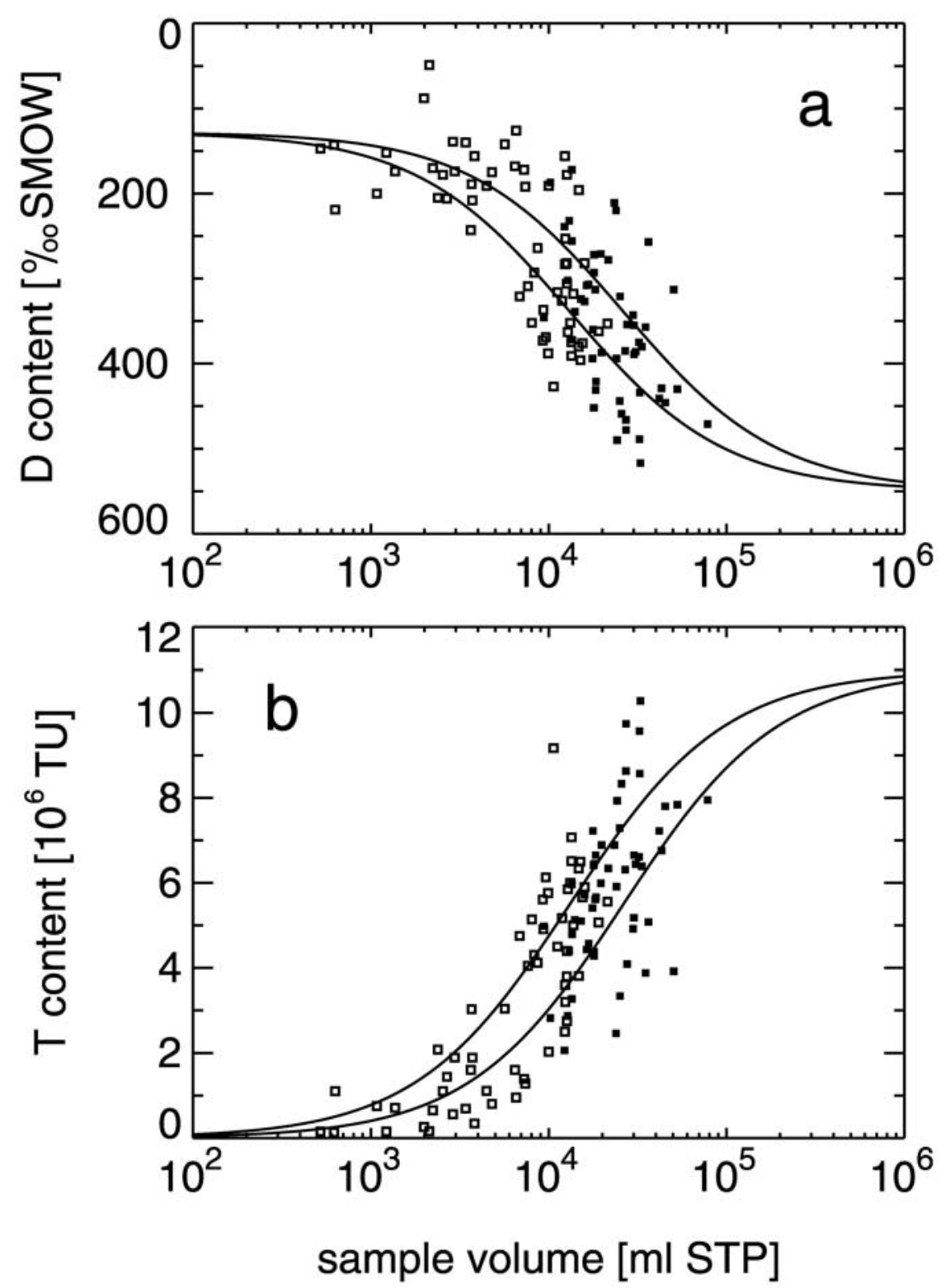

Figure 1. D content and $\mathrm{T}$ content of the recovered water samples as a function of the amount of air collected. Open symbols represent samples through 1978; full symbols represent those after 1978. Only samples collected above $20 \mathrm{~km}$ altitude are shown. The measured T contents were normalized to the date of the first flight, 14.6.1975, by multiplication with an exponential factor with an e-fold time of 5.2 years to compensate for the temporal decay of stratospheric HTO. The curves were calculated assuming that the recovered water is a mix of stratospheric water vapor and wall water (see text).

tried to also retrieve the $\mathrm{D}$ content and mixing ratio of stratospheric water vapor. It is rather a shortcut necessitated by the lack of laboratory simulations and utilizes the information implicitly contained in the measured D content to correct for the amount of wall water contaminating the stratospheric $\mathrm{T}$ content.

\section{HTO Reanalysis}

[12] The recovered amounts of water vapor of the flights prior to 1979 , their measured T and D contents, as well as the corrected $\mathrm{H}_{2} \mathrm{O}$ mixing ratios and isotope contents were tabulated by Pollock et al. [1980]. The measured D and T content from the various flights since 1979, along with sample altitude, sample volume, and other pertinent parameters, are listed in Table A1 in Appendix A. An overview of the $\mathrm{D}$ and $\mathrm{T}$ contents measured in the water samples collected during all 13 balloon flights is given in Figure 1. To compensate for the temporal decay of HTO in the stratosphere, the T contents shown were adjusted to the date of the first flight, 14.6.1975. The adjustment assumes an exponential decay with an e-fold time of 5.2 years, antici- 
pating the results found later in this section. The data are sorted with respect to the air volume collected, a precisely measured sample parameter, and a proxy of the amount of stratospheric water collected. The objective of this plot is twofold: (1) to underline the large degree of isotopic contamination of the samples by wall water and (2) to point to a solution for its correction. As Figure 1 shows, both the D and the $\mathrm{T}$ content in the recovered water varied widely, in the case of $\mathrm{T}$ from virtually 0 to $10 \times 10^{6} \mathrm{TU}$, i.e., from the $\mathrm{T}$ content of wall water to that expected for stratospheric water vapor. However, Figure 1 also demonstrates that the measured $\mathrm{T}$ and $\mathrm{D}$ content correlate strongly with the volume of air collected. The low $\mathrm{T}$ values are invariably connected with small air volumes, indicating that these samples are dominated by wall water; the high $\mathrm{T}$ values are only found for air volumes above $10 \mathrm{~L}$ STP. We also note that the samples collected since 1979 and indicated by the full squares have larger sample volumes. Accordingly, they average higher $\mathrm{T}$ and lower D contents than the earlier flights.

[13] To provide a quantitative perspective, Figure 1 includes two curves which represent, in an idealized fashion, the effect of wall water on the measured $\mathrm{D}$ and $\mathrm{T}$ content. They were calculated on the assumption that the recovered water is a mix of stratospheric water vapor and wall water. These calculated isotope contents are accordingly given by

$$
\begin{aligned}
& D_{m}=D_{s} \times s / t+D_{w} \times w / t \\
& T_{m}=T_{s} \times s / t+T_{w} \times w / t,
\end{aligned}
$$

where $t=s+w$ is the total amount of water, $s$ is the amount of stratospheric water vapor, and $w$ is the amount of wall water. $D$ and $T$ are the $\mathrm{D}$ and $\mathrm{T}$ content. The indices $m, s$, and $w$ refer to measured, stratospheric, and wall water, respectively. The variable $s$ is given by the product of the sample volume and the stratospheric water vapor mixing ratio of 5 ppmv. Two values are assumed for the amount of wall water: $0.065 \mathrm{ml}$ STP $\mathrm{H}_{2} \mathrm{O}$ (gas) and $0.13 \mathrm{ml}$ STP $\mathrm{H}_{2} \mathrm{O}$ (gas). These values bracket the average amount of wall water. The isotopic contents were fixed at realistic values (see below): $D_{w}=-128 \% ; D_{s}=-550 \% ; T_{s}=11 \times 10^{6}$ $\mathrm{TU} ; T_{w}=0 \mathrm{TU}$.

[14] These curves explain the observed data reasonably well; in fact, although describing average conditions only, they appear to explain much of the observed variance in the $\mathrm{D}$ and $\mathrm{T}$ content. Moreover, they also demonstrate that the dependence of the $T$ content on sample volume is quite similar to that of the $\mathrm{D}$ content. This indicates that the admixture of wall water to stratospheric water affects both isotopes in the same manner and gives credit to the assumption that the measured isotope contents are the result of a mix of stratospheric and wall water. Finally, they allow an estimate of the average amount of wall water during all the flights. The amount of wall water equals that of the stratospheric water collected, when the measured isotope content lies midway between the values for wall water and stratospheric water. According to Figure 1, this corresponds to an air volume of $20 \mathrm{~L} \mathrm{STP}$ at 5 ppmv $\mathrm{H}_{2} \mathrm{O}$.

[15] In principle, the relation of the measured $\mathrm{T}$ content with the sample volume would allow formulation of a correction for the contribution of wall water and therefore the retrieval of the stratospheric $\mathrm{T}$ content from that of the water collected. However, the retrieval would not be very precise. Obviously, the scatter of the $\mathrm{T}$ content for a given sample volume is still rather large, most likely owing to the variance in the amount of wall water for different samples [see Pollock et al., 1980]. Moreover, the relation between T content and sample volume is not a simple, e.g., linear one. Finally, there are no samples with sufficiently large sample volumes whose $\mathrm{H}_{2} \mathrm{O}$ would unequivocally represent stratospheric $\mathrm{T}$ values. Thus we prefer another solution.

[16] Eliminating $s / t$ from equations (1) and (2) yields a linear relation between the measured $\mathrm{D}$ and $\mathrm{T}$ content

$$
D_{m}-D_{w}=\left(D_{s}-D_{w}\right) \times T_{m} / T_{s} .
$$

As long as the values for $D_{s}, D_{w}$, and $T_{s}$ remain fixed, $D_{m}$ correlates linearly with $T_{m}$. The measured data pairs $D_{m}, T_{m}$ fall on the so-called mixing line which connects the points $D_{s}, T_{s}$ and $D_{w}, T_{w}=0$. This suggests that the measured D contents could serve as a measure of the actual amounts of wall water that contaminate the stratospheric $\mathrm{T}$ contents and thus as a means for correction.

[17] In Figure 2 we investigate the linear correlations between the measured $\mathrm{D}$ and $\mathrm{T}$ contents $D_{m}, T_{m}$, first for the individual flights. They are ordered according to the year of sampling to visualize the temporal decay of the stratospheric HTO. Figure 2 includes only data collected above 20 $\mathrm{km}$ altitude. The lower stratosphere exhibits a high variance in the T content owing to the variable admixture of tropospheric air [Mason and Östlund, 1979]. Moreover, most of the gradient between the high stratospheric T contents and the low tropospheric ones is located there [Mason and Östlund, 1979; Östlund and Mason, 1979] (see also Figure 4). This natural variance and correlation would superimpose onto and partially mask the correlation induced by the isotopic exchange with wall water, which we would like to extract here. For the same reason the samples at 21.2 and $22.6 \mathrm{~km}$ altitude from flight 20 were left out because they were influenced by a recent thermonuclear test explosion (see also Figure 4).

[18] The measured $\mathrm{T}$ and $\mathrm{D}$ contents from the individual flights are clearly linearly correlated. The correlation coefficients and the expressions for the corresponding regression lines are listed in the caption of Figure 2. The correlations are quite close for the years 1975 to 1978 but less so for the later years, especially for 1979 and 1983. This may point to structure in the vertical profile of the $\mathrm{T}$ content even above $20 \mathrm{~km}$ altitude. For instance, the profile from flight 25 in 1979 over Ceara, Brazil exhibits a linear increase in the $\mathrm{T} / \mathrm{H}$ ratio with altitude (see Figure 4).

[19] The intersects of the regression lines at $T=0$ give the $\mathrm{D}$ content of wall water, $D_{w}$. It represents the average $\mathrm{D}$ content of all the water absorbed on the inner surfaces that came into contact with the stratospheric air samples, such as the various parts of the sampling and recovery system. Apparently, $D_{w}$ varied between years. The total range in $D_{w}$ was $-50 \%$ to $-200 \%$. The value of $D_{w}$ averaged over all flights was $-128 \pm 44 \%$. It can be extracted from the correlation for all flights between 1975 and 1983, which is quite good and also included in Figure 2. In that case the T content was adjusted for its temporal decay just as in Figure 1 by multiplication with an exponential factor, $\exp (t / 5.2)$, where $t$ is the time in years since the first flight on 

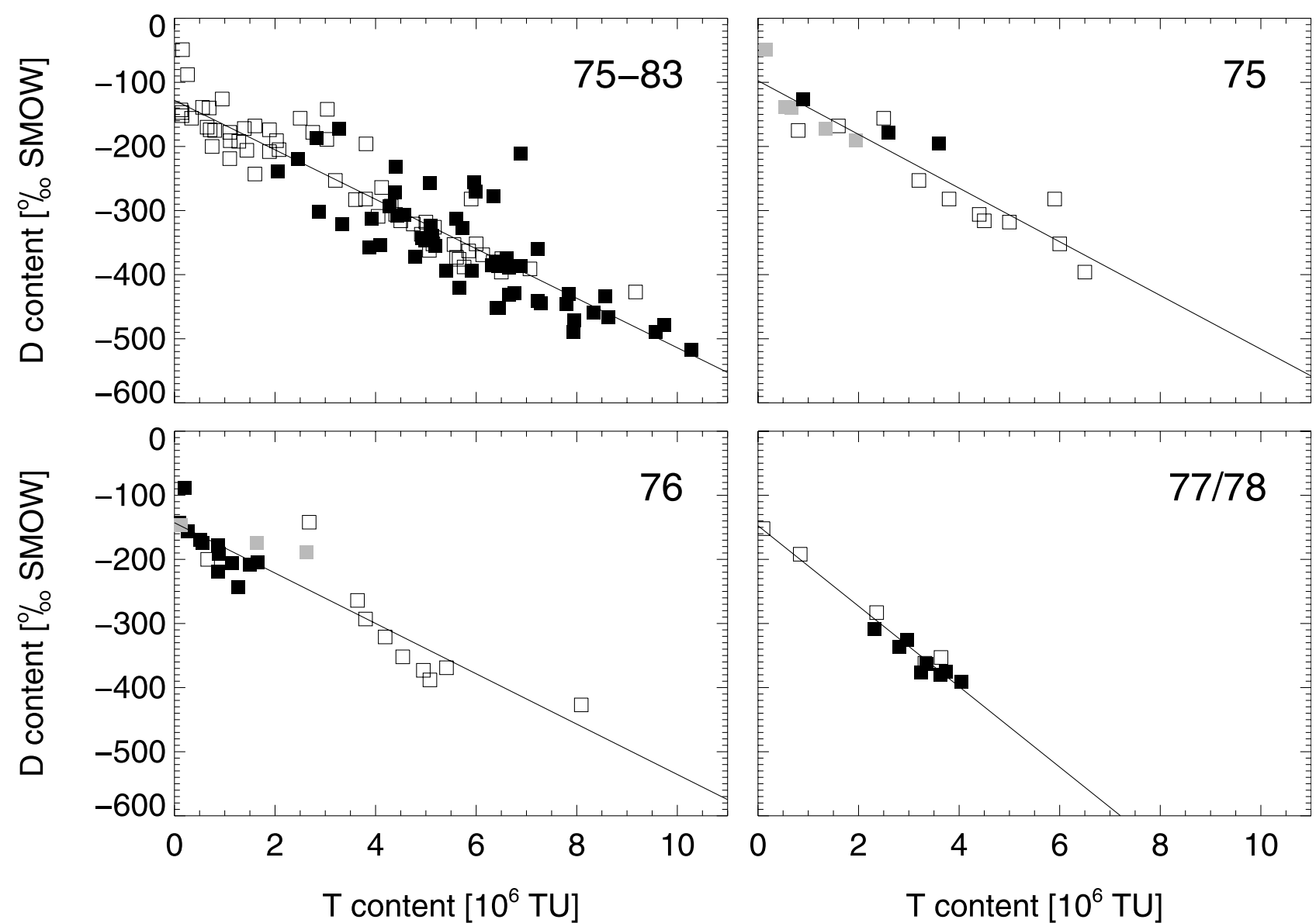

Figure 2. Correlation of the $\mathrm{D}$ and $\mathrm{T}$ contents measured in the recovered water samples. Only samples collected above $20 \mathrm{~km}$ altitude are included. Samples from several flights are aggregated into annual plots as indicated in the upper right corner. Darker-shaded symbols refer to the later flights in the respective aggregate. The first panel shows the aggregate over all years; there the T contents are normalized to the date of the first flight, 14.6.1975, by multiplication with an exponential factor with an e-fold time of 5.2 years to account for the temporal decay of stratospheric HTO. The straight lines represent linear regressions fitted to the data. The numerical expressions are $(1975-1983): D=-(128 \pm 44)-(38.6 \pm 1.7)$ $\times T ; c=-0.9088,(1975): D=-(98 \pm 34)-(42 \pm 4) \times T ; c=-0.934,(1976): D=-(143 \pm 73)-(39 \pm 4)$ $\times T ; c=-0.916,(1977,1978): D=-(148 \pm 14)-(63 \pm 3) \times T ; c=-0.984,(1979): D=-(165 \pm 71)-$ $(70 \pm 71) \times T ; c=-0.492,(1981): D=-(198 \pm 36)-(104 \pm 18) \times T ; c=-0.803,(1982): D=-(192 \pm$ $45)-(116 \pm 28) \times T ; c=-0.771,(1983): D=-(127 \pm 49)-(188+70) \times T ; c=-0.741$, where $D$ is the $\mathrm{D}$ content in \%o (SMOW) and $T$ is the T content in $10^{6} \mathrm{TU} ; c$ is the respective linear correlation coefficient.

14.6.1975. This average $D_{w}$ was used as input parameter for the D curves in Figure 1; it is in good agreement with the value for wall water found by Pollock et al. [1980].

[20] The good quality of these linear D/T correlations also suggests a simple way of correcting for the contribution of wall water: The extrapolation along the regression lines in Figure 2 to the stratospheric D content will yield the corresponding stratospheric T content. Although the actual $\mathrm{D}$ contents of water vapor for the present samples are not known, average vertical profiles of the D content in the stratosphere are available in the literature. The average D content over the altitude range considered here, 20 to 40 $\mathrm{km}$, is $-550 \%$ [Moyer et al., 1996]. This is also the D content used to derive the D curves in Figure 1 and appears to be quite consistent with the $\mathrm{D}$ measurements reported here. As a first step, this extrapolation leads to annually and vertically averaged stratospheric $\mathrm{T}$ contents.
[21] The so-obtained annually averaged stratospheric $\mathrm{T}$ contents are included in Figure 5 below (open triangles), which describes the time dependence of the stratospheric $\mathrm{T}$ content above $20 \mathrm{~km}$ altitude. They closely follow an exponential decay curve of $(11.36 \pm 1.0) \times 10^{6} \times \exp (t / 5.3 \pm$ $0.33)) \mathrm{TU}$ and give a first estimate of the decay time of the stratospheric $\mathrm{T}$ content, namely $\tau=5.3 \pm 0.33$ years.

[22] The variable $\tau$ can also be determined from the $D_{m} / T_{m}$ correlation for the data from all flights (cf. Figure 2, panel " $75-83$ "). Obviously, the quality of that correlation will vary with the $\tau$ chosen to adjust for the exponential decay in the stratospheric $\mathrm{T}$ content. It should maximize for the correct $\tau$. Figure 3 shows the coefficient of that correlation $c$ as a function of $\tau$. It shows a clear maximum at a decay time of 5.15 years and $c \sim-0.91$. Since the maximum is quite well defined, the error in the $\tau$ so determined must be small, i.e., $<0.1$ year. This procedure has the added advant- 

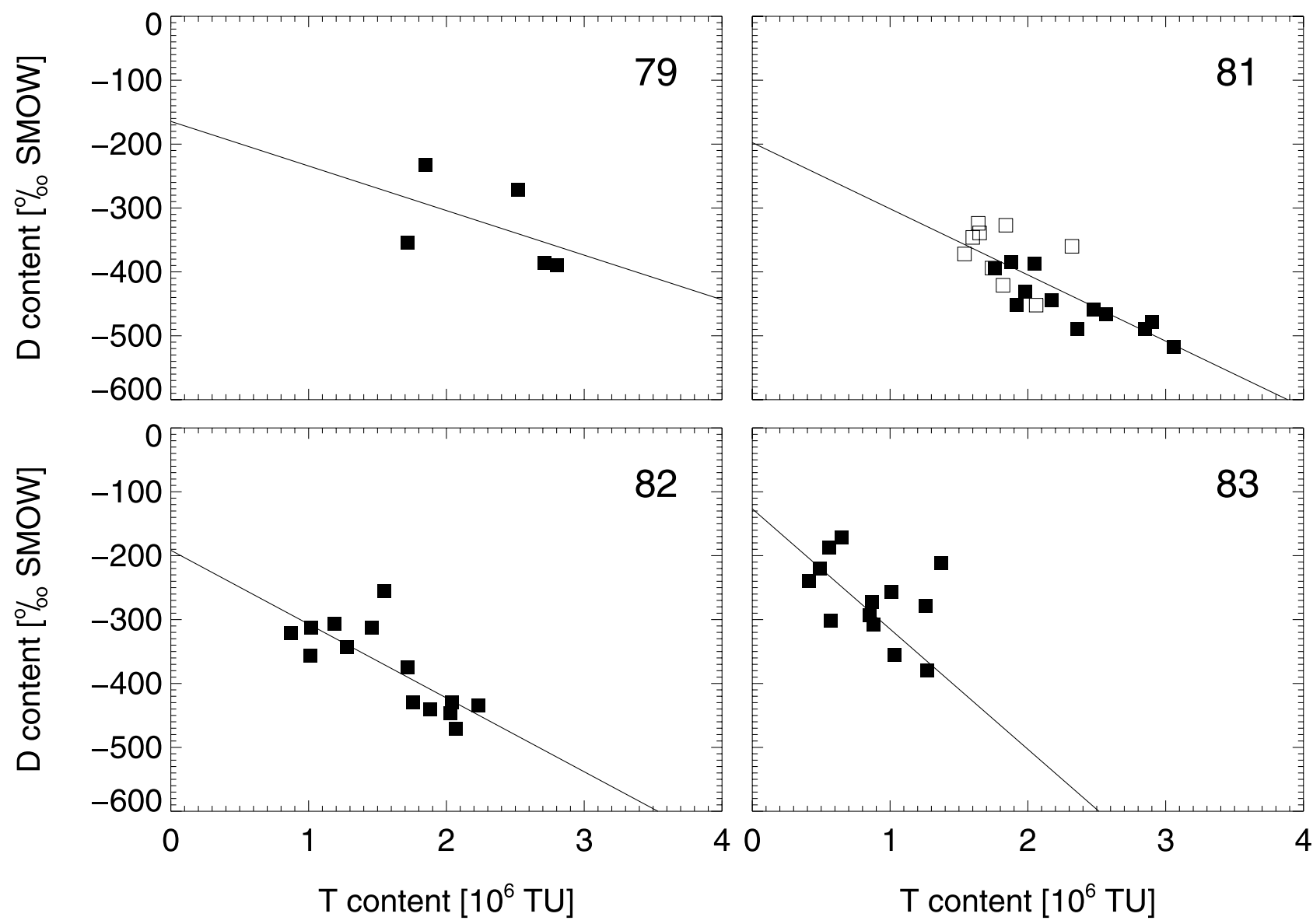

Figure 2. (continued)

age that no assumption about the average stratospheric D content had to be made. The only assumptions are (1) the temporal change in the $D_{m} / T_{m}$ relations is due to the decay in T and not, for instance, in D and (2) the decay is exponential. Both assumptions are quite plausible. Thus we have already at this point achieved one goal of our reanalysis, namely the determination of the decay time of the $\mathrm{T}$ content in the middle and upper stratosphere. The two estimates of $\tau$ average to 5.2 years. This is the value we have used for normalizing the T contents in Figures 1 and 2, panel " $75-$ 83 ", to a common date.

[23] The low scatter in the correlations for the earlier flights indicates not only that the D content of wall water was fairly stable but also that the T content and D content of stratospheric water vapor, which define the other end point of the mixing line, must have varied along the mixing line if they varied at all. In other words, the vertical profiles of the $\mathrm{D}$ and $\mathrm{T}$ content were either constant with altitude or varied with altitude at a fixed relation to each other given by the slope of the mixing line. At a first glance the latter seems quite unlikely. However, the stratospheric oxidation of $\mathrm{CH}_{4}$ produces water vapor with a D content of $-80 \%$ and a $\mathrm{T}$ content of $10^{4} \mathrm{TU}$, which generates an increase in the mixing ratio, an increase in the $\mathrm{D}$ content, and a decrease in the $\mathrm{T}$ content of water vapor with increasing altitude [Pollock et al., 1980; Moyer et al., 1996]. These isotopic values for $\mathrm{CH}_{4}$ are close enough to the isotopic composition to wall water that the vertical gradients in the $\mathrm{D}$ and $\mathrm{T}$ content introduced by them would add no detectable scatter to the $D_{m} / T_{m}$ correlations. As we shall see below, the gradients in the $\mathrm{T}$ contents of the earlier flights were generally small. To a lesser extent this is also true for the later flights. Although the scatter is larger there, it is still narrow enough to indicate that structures in the vertical profiles of the D and T content above $20 \mathrm{~km}$ altitude could not have been large.

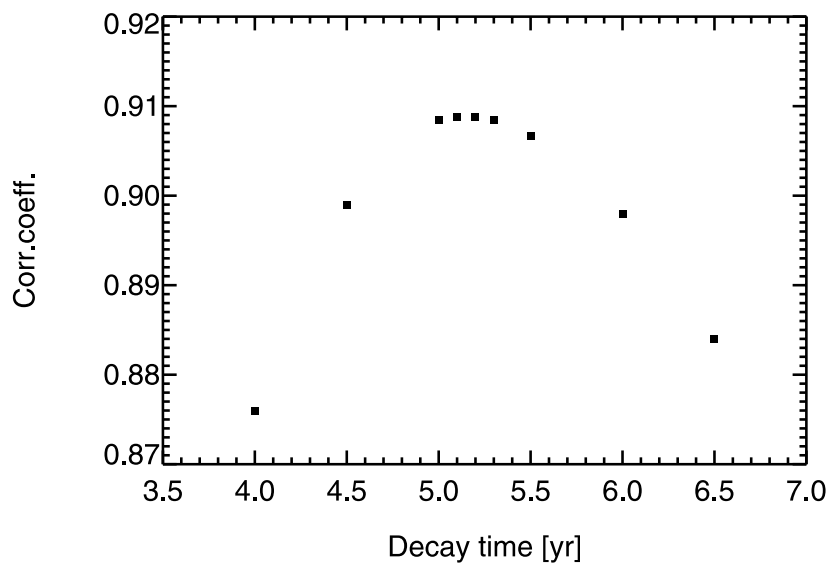

Figure 3. The correlation coefficient between $\mathrm{D}$ and $\mathrm{T}$ content for all flights, 1975-1983, as a function of the efold time used in the decay correction. 
[24] This low scatter in the correlations also encouraged us to attempt the correction of individual $\mathrm{T}$ data points. The extrapolation for a single measured $\mathrm{D} / \mathrm{T}$ data point can be made in two different ways. One is to draw a straight line between the appropriate point for wall water, e.g. $-128 \%, 0$ TU, and the measurement point $D_{m}, T_{m}$ and extrapolate that line until it intersects the stratospheric D content of $-550 \%$. The other is to draw a straight line with a slope determined from the appropriate annual regression line through the measured $\mathrm{D} / \mathrm{T}$ data point and extrapolate it to intersect the line of stratospheric D content. In the following, we will favor the second approach because the errors in the slopes are relatively small and it avoids the problem of small differences between large and uncertain numbers. This approach works well for the data from the years 1975 to 1978 , where the correlations are good with $\mid$ coefficients $\mid \geq$ 0.92 . However, the correlations of the later years are not as good. For these data we introduce an averaging and scaling procedure to calculate the slopes. It is based on the $D_{m} / T_{m}$ correlation for all flights which has a correlation coefficient of -0.91 and a regression line of $D=(-128 \pm 44)-(38.6 \pm$ $1.7) \times \mathrm{T}$, where $D$ is given in $\%$ and $T$ is given in $10^{6} \mathrm{TU}$. Its slope, -38.6, which holds for 16 June 1975, multiplied with the exponential factor, $\exp (t / 5.2)$, where $t$ is the time in years since that date, provides the slopes for the flights after 1978. Because of the higher correlation coefficient and lower error in the slope of the $D_{m} / T_{m}$ relation for all data, the so-derived slopes for the individual flights are expected to be more accurate than those derived individually from those flights. This should result in more accurate vertical profiles of the $T$ content for the years 1979-1983, which in turn should provide a more accurate estimate of the temporal decay of the $\mathrm{T}$ content in stratospheric water vapor (see section 4 ).

[25] For the calculation of the actual correction terms we introduce another refinement. We allow the stratospheric D content to be altitude dependent. The average altitude dependence is taken from the Atmospheric Trace Molecule Spectroscopy Experiment (ATMOS) data, which provide nearly global measurements of the D content in stratospheric water vapor [Moyer et al., 1996]. They as a matter of course include the vertical increase in the D content due to $\mathrm{CH}_{4}$ oxidation. Between 17.5 and $35 \mathrm{~km}$ altitude that dependence can be approximated by $D_{s}(\mathrm{SMOW})=-550+$ $2.7 \times(z-30)$, where $z$ is the altitude in $\mathrm{km}$ and $D_{s}$ is given in \%o. $D_{s}$ above $35 \mathrm{~km}$ altitude is assumed to be constant at $-500 \%$, and below $17.5 \mathrm{~km} D_{s}=-580-25.2 \times$ $(z-17.5)$. The correction of the measured $\mathrm{T}$ content in a sample from the individual flight $i, T_{m, i}$, to the actual stratospheric $\mathrm{T}$ content, $T_{s, i}$, is then given by

$$
T_{s, i}=T_{m, i}+\left(D_{s}(z)-D_{m, i}\right) / s_{i}
$$

where $s_{i}$ is the slope for the individual flight or year $i$ and $D_{m, i}$ is the measured D content in that same sample. The socorrected $\mathrm{T}$ contents of the later flights are also given in Tables A1 to A5 in Appendix A. The corrected T contents from all flights are plotted as vertical profiles in Figure 4.

\section{Discussion}

[26] The present method of correction has the advantage that it recovers stratospheric $\mathrm{T}$ contents from all measure- ments, not just from a selected few as in the method given by Pollock et al. [1980]. Moreover, it does so in a global way without the need to investigate amounts and isotope contents of wall water from the various parts of the sampling and recovery system. Instead, it relies on the information about the contamination implicit in the measured $\mathrm{D}$ content. The method requires the knowledge of the stratospheric D content. That is available only as an average and not for the actual air sampled. That is, the correction removes some of the natural variance in the $\mathrm{D}$ content and thus in the retrieved $\mathrm{T}$ content. This is probably not a serious problem. As already mentioned in section 3, the good correlation between measured D and T contents in the early flights also indicates that the spread in the stratospheric D content was not large. At least during those flights, the stratospheric D values must have been close to the average.

[27] In addition, the use of the slopes as the method for correction also introduces a tendency to smooth the vertical profiles of the $\mathrm{T}$ content. Much of the variance that is suppressed owing to these two factors is captured by the estimated errors of the $\mathrm{T}$ content. They are also shown in Figure 4 and mostly range between $10 \%$ and $20 \%$ (see also Tables A1 to A5 in Appendix A). The error analysis assumes an absolute error of $44 \%$ in both the measured and the assumed stratospheric D contents. It further accounts for the measurement error in $T_{m, i}$ (see Tables A1 to A5 in Appendix A) and that derived for the slopes. The error assumed for D contents is based on that derived for average wall water. It is certainly an overestimate of the measurement error of $D_{m, i}$. Since the vertical increase of $D_{s}(z)$ is $\sim 80 \%$ over the altitude range considered, $\pm 44 \%$ o should be also a good estimate of the error in $D_{s}(z)$ at altitudes above $20 \mathrm{~km}$. The variance in $D_{s}(z)$ below $20 \mathrm{~km}$ altitude could well be larger. Nevertheless, for lack of a better alternative we use the same error in $D_{s}$ at these altitudes as well.

[28] The $\mathrm{T}$ contents in Figure 4 are plotted against the height above the tropopause on the day of the balloon flight. That height is given in the lower left corner of each panel. It was obtained in pressure coordinates from the National Centers for Environmental Protection (NCEP) reanalysis (see http://www.cdc.noaa.gov/HistData/) for the location of the respective balloon flight and averaged over the day of the flight. The pressure coordinates were converted to geometric altitude using the U.S. Standard Atmosphere for the appropriate season and latitude. The lowest altitudes reached by the balloon measurements were usually significantly higher than the tropopause. Therefore these measurements were extended to lower altitudes by data from the Project Airstream, which provided airborne HTO measurements up to $20 \mathrm{~km}$ altitude. The measurements were made by Östlund and Mason. The earlier data were given by Ostlund and Mason [1979] and Mason and Östlund [1979]; the full data file is available from the Carbon Dioxide Information Analysis Center, Oak Ridge, Tenn. (http:// cdiac.esd.ornl.gov.ftp/db1019/foxidata/tritium.xls). Airstream data are incorporated whenever the date of sampling is within 1 month of the respective balloon flight and the location within $5^{\circ}$ latitude and longitude. An exception is the location Yorkton, Canada, because at that latitude, $52^{\circ} \mathrm{N}$, Project Airstream sampled at $\sim 125^{\circ} \mathrm{W}$ longitude, i.e. over the Pacific. We also note that the $\mathrm{T}$ measurements during Airstream determined the mixing ratio of HTO. To convert 

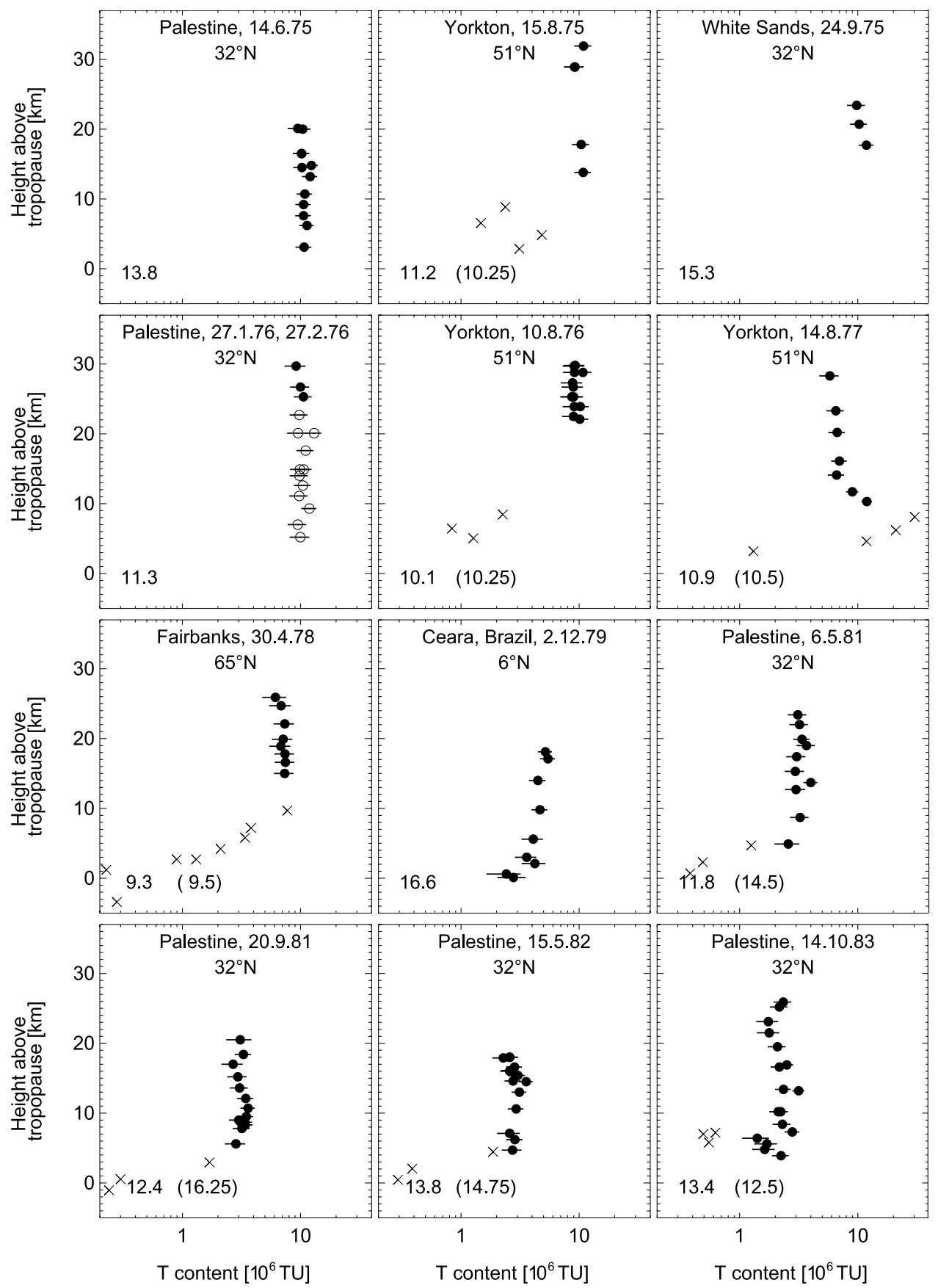

Figure 4. Vertical profiles of the corrected T content. Dates and locations of the balloon flights are given in the figure. The height is counted from the tropopause. The height of the tropopause at the location and date of each balloon flight is given by the figure in the lower left of each panel. Error bars represent the standard deviation. Also shown are T contents in the lower stratosphere estimated from $\mathrm{T}$ measurements during Project Airstream (crosses). The corresponding tropopause height is given by the figures in the parentheses (see text).

it into a $\mathrm{T} / \mathrm{H}$ ratio, the mixing ratio of $\mathrm{H}_{2} \mathrm{O}$ has to be known. That parameter was not measured during Airstream. For the conversion we use an average value of 4.5 ppmv $\mathrm{H}_{2} \mathrm{O}$ in the lower stratosphere for the locations and seasons considered [cf. Abbas et al., 1996; Chang et al., 1996; Randel et al., 1998]. The error in the T/H ratio introduced by the assumption of a constant $\mathrm{H}_{2} \mathrm{O}$ mixing ratio is $<10 \%$ for the flights considered and is negligible compared with the variance in
HTO in the lower stratosphere. The height of the tropopause at the location and time of sampling of the Airstream data was also taken from the NCEP reanalysis. Because the Airstream profiles were collected on several consecutive aircraft flights, these tropopause heights represent averages over at least 3 days.

[29] Since latitude, longitude, and date of sampling of the Airstream data do not exactly match those of the balloon 
flights, they are not a true extension of the balloon profiles. Moreover, they were sampled and measured quite differently; in addition, they require different a priori knowledge to compensate for missing parameters. Nevertheless, the data from Airstream are quite consistent with the balloon measurements corroborating the validity of our correction procedure. In any case they serve well to complete the vertical stratospheric $\mathrm{T}$ profiles down to the tropopause and demonstrate that nearly all of the transition from the high $\mathrm{T} / \mathrm{H}$ ratios in the upper and middle stratosphere to the low values in the troposphere takes place in the lower stratosphere. There is an indication that the zone of transition is deeper at more northern latitudes, $\sim 10 \mathrm{~km}$ at Fairbanks, Alaska, $65^{\circ} \mathrm{N}$, and shallower at midlatitudes, $\sim 5 \mathrm{~km}$ at Palestine, Texas, $32^{\circ} \mathrm{N}$.

[30] The balloon data themselves generally show little variation with altitude, with two notable exceptions. One is the flight over Yorkton on 14.8.1977, which shows an increase in the $\mathrm{T}$ content towards lower altitudes. This is a unique feature. It is, however, corroborated by the Airstream data, which demonstrate extremely high $\mathrm{T}$ contents in the lower stratosphere with a maximum of $31 \times 10^{6} \mathrm{TU}$ at $8 \mathrm{~km}$ above the tropopause. This unique distribution is the result of a Chinese test explosion over Lop Nor, $41^{\circ} \mathrm{N}$ latitude on 17 November 1976 . With a total yield of 4 MT and a fusion yield of 1.3 MT it injected $19 \mathrm{MCi}$ HTO into the stratosphere, mostly (85\%) below $20 \mathrm{~km}$ altitude [Mason et al., 1982]. Remnants of that injection are clearly visible in the profile from 14.8.1977; some may even be left in the profile from 30.4 .1978 , nearly a year later. The other exception is the tropical flight on 2.12.1979, which exhibits a significant increase in the T content over the full altitude range covered by the balloon, i.e., from nearly the tropopause to $20 \mathrm{~km}$ above it. This feature is not implausible either; it may be caused by the dilution of HTO with $\mathrm{H}_{2} \mathrm{O}$ carried upward by the Brewer-Dobson circulation. Possible variations with altitude in the other balloon profiles are smaller in vertical scale and appear too small in amplitude compared with the measurement error to be considered significant. Incidentally, the one vertical profile of the $\mathrm{T}$ content which the previous correction method and analysis considered reasonably reliable is that over Fairbanks on 30.4.1978 [Pollock et al., 1980]. The corrected T contents from that analysis were $\sim 30 \%$ lower than the present values. The difference is probably due to an underestimate of the total amount of wall water in the earlier analysis.

[31] The other significant and important feature in the sequence of these profiles is the strong decrease in the $\mathrm{T}$ content of stratospheric $\mathrm{H}_{2} \mathrm{O}$ with time. Between the first balloon flight and the last one, the $\mathrm{T}$ content drops from $\sim 11 \times 10^{6}$ TU to $2.3 \times 10^{6} \mathrm{TU}$, i.e., nearly a factor of 5 over not quite a decade. To bring out the temporal decay of the $\mathrm{T}$ content more clearly, the $\mathrm{T}$ profiles in Figure 4 were averaged over altitude and plotted against time. Because of the uneven coverage and higher variance in the lower stratosphere only measurements above $20 \mathrm{~km}$ were included. Also omitted were the lowest two balloon data points of the flight over Yorkton 14.8.1977, which were polluted by a recent thermonuclear test explosion over Nop Lor, 1976. The resulting decay is shown in Figure 5a. Within the error of the averages it is quite consistent with an exponential decrease. A straight line fitted to the
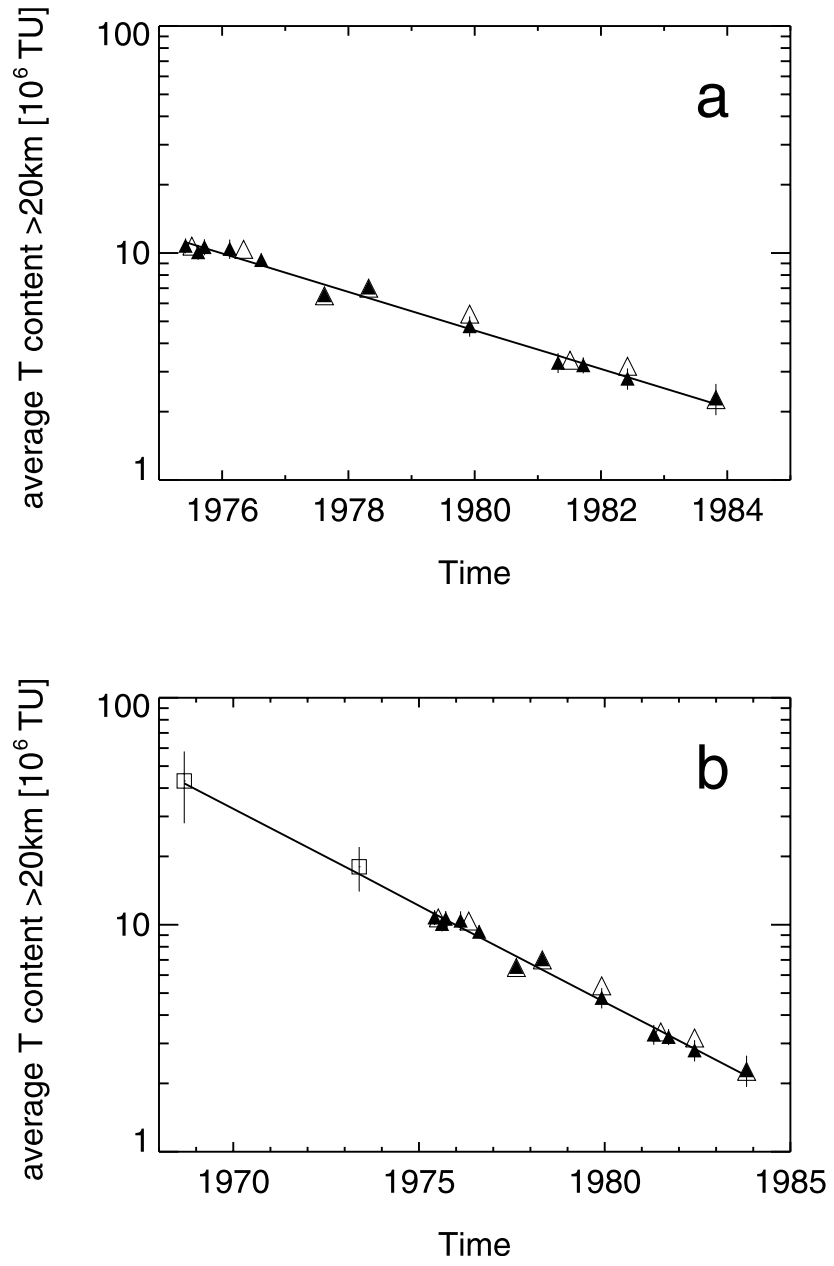

Figure 5. Temporal decay of the average $\mathrm{T}$ content in the stratosphere. Full triangles represent the average $\mathrm{T}$ content above $20 \mathrm{~km}$ altitude derived from the profiles of the corrected $\mathrm{T}$ content in Figure 4. Open triangles represent the average $\mathrm{T}$ content derived from the extrapolation of the regression lines in Figure 2 to a D content of $-550 \%$ o (see text). The straight line represents a fit to the full triangles. It corresponds to an exponential decay: $T=(11.16 \pm 0.75) \times$ $10^{6} \times \exp (-t /(5.12 \pm 0.18))$ TU. The lower panel includes the results from two earlier rocket flights (squares). All error bars represent standard deviations.

$\log (\mathrm{T}$ content $)$ corresponds to $T=(11.16 \pm 0.75) \times 10^{6} \times$ $\exp (-t /(5.12 \pm 0.18))$ TU. The direct nonlinear fit of an exponential to these data gives $T=(11.11 \pm 0.23) \times 10^{6} \times$ $\exp (-t /(5.24 \pm 0.28)) \mathrm{TU}$, in good agreement. This can be compared with the average T contents derived from the $T_{m} /$ $D_{m}$ correlations, which are indicated by the open triangles in Figure 5a. They yield an exponential decay of $T=(11.36 \pm$ $1.0) \times 10^{6} \times \exp (-t /(5.30 \pm 0.33)) \mathrm{TU}$.

[32] There are no other historic balloon data against which these $\mathrm{T}$ contents could be compared. There are, however, two rocket flights, which provided measurements of the HTO mixing ratio in the upper stratosphere. Both were launched from the White Sands Missile Range, New Mexico, $\sim 31^{\circ} \mathrm{N}$ latitude. The first was flown on 4.9 .1968 and gave a HTO mixing ratio of $(0.97 \pm 0.04) \times 10^{10} \mathrm{HTO} / \mathrm{kg}$ 
air for the altitude range from 44 to $62 \mathrm{~km}$ [Scholz et al., 1970]. To convert this mixing ratio to a $\mathrm{T}$ content, we assume a water vapor mixing ratio of $5.5 \mathrm{ppmv}$ [see Randall et al., 1998] with an uncertainty of $\pm 2 \mathrm{ppm}$. With that assumption we obtain a T content of $(43 \pm 15) \times 10^{6} \mathrm{TU}$ for that flight.

[33] The second flight was launched on 23.5.1973. It collected a total amount of HTO of $(13.5 \pm 0.57) \times 10^{6} \mathrm{TU}$ $\mathrm{mgH}_{2} \mathrm{O}$ for the altitude range of 40.8 to $50.6 \mathrm{~km}$ [Ehhalt et al., 1975]. In that case the amount of stratospheric water vapor collected could also be measured with reasonable precision. It was $0.76_{-0.18}^{+0.25} \mathrm{mg}$. This corresponds to a mixing ratio of $4_{-0.9}^{+1.3}$ ppmv. From the division of these two numbers a $\mathrm{T}$ content of $\left(18_{-6}^{+4}\right) \times 10^{6} \mathrm{TU}$ is calculated. In the lower panel of Figure 5 the balloon data are compared with the rocket data. They lie on the same decay curve, somewhat surprisingly considering the different altitude ranges. However, the uncertainties of the rocket data are large, and they do not provide much of a constraint on the estimated decay time. They were not entered into the calculations. Nevertheless, the rocket data lend strong support to the idea that the decay in the T content of water vapor in the middle and upper stratosphere observed between 1975 and 1983 is a consequence of the large injections of HTO into the stratosphere prior to 1963 . They also support the idea that this decay is exponential and governed by a single e-fold time of 5.12 years over the time period observed.

[34] There are several processes which contribute to that decay in T content. Obviously, the dominant one is the transport of HTO into the troposphere, and it is the e-fold time for this process, $\tau_{\text {tr }}$, which we want to develop here. The next important one is the radioactive decay of HTO within the stratosphere. It proceeds with an e-fold time of 17.8 years. In addition there are some minor modifications: The measured $\mathrm{T}$ content represents a $\mathrm{T} / \mathrm{H}$ ratio, which will also respond to any temporal change in the stratospheric $\mathrm{H}_{2} \mathrm{O}$ mixing ratio. Moreover, it will be influenced by HTO injected by thermonuclear test explosions during or immediately prior to the observation period, and it will be influenced by the natural cosmogenic production of $\mathrm{T}$ in the stratosphere. In the following, we address these contributions starting with the minor ones.

[35] As indicated in the introduction cosmogenic production maintains a background $\mathrm{T}$ content which averages $5 \times$ $10^{5} \mathrm{TU}$. For $32^{\circ} \mathrm{N}$ latitude, where most of the measurements were made, this figure almost certainly represents a substantial overestimate because most of that $\mathrm{T}$ production takes place at high latitudes and there partly at lower altitudes [ $\mathrm{Lal}$ and Peters, 1962]. This leads to a nonuniform HTO field which favors the polar regions. In addition, HTO is removed from the lower polar stratosphere much more readily than implied by the 5-year removal time used in the estimate of the cosmogenic HTO background. It therefore contributes less to the stratospheric HTO burden than implied by the simple product of average cosmogenic production rate and mean stratospheric lifetime. In any case this natural $\mathrm{T}$ content is substantially smaller than the T content of $2.5 \times 10^{6} \mathrm{TU}$ measured during the last balloon flight in 1983. Moreover, the presence of a significant natural HTO background should cause a deviation from a simple exponential decay. To account for a constant natural background in the $\mathrm{T}$ content we have also fitted a relation $T=\mathrm{A} \times \exp (-t / \tau)+\mathrm{B}$ to the data in Figure 5. The result is $T=(12.15 \pm 1.75) \times 10^{6} \times$ $\exp (-t /(6.23 \pm 1.69))-(1.12 \pm 1.86) \times 10^{6} \mathrm{TU}$.

[36] The so-obtained value for the background $B$ is negative and not significantly different from 0 . Its actual value must be small and cannot be determined from the present data. We will neglect the effect of cosmogenic background in our further analysis and continue to assume a simple exponential decay. With a forced positive background $B=0.5 \times 10^{6}$ TU the fit would result in a $\tau=4.6$ years, $10 \%$ lower than that obtained from the simple exponential decay.

[37] The balloon profile from 14.8.1977 shows clear evidence of a perturbation from the nuclear test on 17.11.1976. There was another minor test during the observation period on 16.10 .1980 . It released $\sim 2.1 \mathrm{MCi} \mathrm{HTO}$ into the lower stratosphere, about a factor of 10 less than the test in 1976 [Mason, 1985]. Although influencing altitudes below $20 \mathrm{~km}$, it apparently did not inject HTO above that altitude. Finally, there was a larger test on 27.6.1973, which could have influenced the balloon data. It released $19 \mathrm{MCi}$ HTO, 95\% of which remained below $20 \mathrm{~km}$ altitude [Mason et al., 1982]. Much of that HTO had been removed before the date of the first balloon flight on 14.6.1975, such that the impact of that test explosion on these data should have been a factor of 10 lower than that of the explosion on 17.11.1976 on those obtained from the flight on 14.8.1977, i.e., it should be negligible. Thus the only concern is the influence of the nuclear test from 17.11.1976. That influence was accounted for simply by omitting the two lowest data points from the flight on 14.8.1977, which were clearly impacted. This changes the average $\mathrm{T}$ content of that flight from $7.65 \times 10^{6} \mathrm{TU}$ to $6.53 \times 10^{6} \mathrm{TU}$. No correction was made for the subsequent flight on 30.4.1978, whose T/H profile might still indicate a slight remnant of the test in 1976. In fact the average T content from that profile slightly exceeds that from the flight in 1977. The difference, however, is within the scatter of the other averages and could also be due to the difference in latitude between the two flights. Thus apart from the flight on 14.8.1977 there is little indication from the balloon data themselves of a significant influence of recent nuclear tests on the decay rate in the $\mathrm{T}$ content above $20 \mathrm{~km}$ altitude. The reason probably is that the initial radioactive cloud of these explosions remained below $20 \mathrm{~km}$ altitude and further, that the lower stratosphere at mid latitudes is rapidly flushed by exchange with the troposphere. For example, Mason et al. [1982] found that the HTO injected by the test explosion in 1976 was removed from the lower stratosphere with an e-fold time of 1.2 years. As a consequence, only a small fraction of the so-injected HTO penetrated to higher altitudes. We therefore consider the influence of later thermonuclear explosions on the derived decay rate as minor on the whole and as accounted for in the case of the flight in 1977.

[38] There is good indication that the mixing ratio of stratospheric $\mathrm{H}_{2} \mathrm{O}$ may have increased over the past 50 years, with an average rate of $\sim 1 \% \mathrm{yr}^{-1}$ [SPARC, 2000]. Such an increase would translate into a decay of the Tcontent of $1 \% \mathrm{yr}^{-1}$, compared with a decrease of $20 \%$ $\mathrm{yr}^{-1}$ actually observed. For the time period 1975-1983 and main latitude $32^{\circ} \mathrm{N}$ considered here, however, no data are available, such that a proper account of this effect cannot be made. In any case its consideration will increase 
the e-fold time assigned to the decay of HTO, $\tau_{\text {HTO }}$, by a corresponding amount: A concurrent increase in $\mathrm{H}_{2} \mathrm{O}$ of $1 \% \mathrm{yr}^{-1}$ leads to $\tau_{\text {HTO }}=1.05 \tau$.

[39] The increase in stratospheric $\mathrm{H}_{2} \mathrm{O}$ may have been accompanied by a change in the $\mathrm{D}$ content of stratospheric water vapor. The temporal increase in the global $\mathrm{CH}_{4}$ mixing ratio and the resulting increase in stratospheric $\mathrm{H}_{2} \mathrm{O}$ from $\mathrm{CH}_{4}$ oxidation, $\sim 0.2 \% \mathrm{yr}^{-1}$ at $30 \mathrm{~km}$ altitude between 1975 and 1983, must have caused a slight increase in the $\mathrm{D}$ content of stratospheric $\mathrm{H}_{2} \mathrm{O}$. This contribution alone should amount to a change of $\delta(\mathrm{SMOW})=10 \%$ over the time period considered here. Since our T correction for wall water is based on the $\mathrm{D} / \mathrm{T}$ correlations, this effect would also slightly influence the derived decay rate for the $\mathrm{T}$ content. It counteracts to some degree the direct contribution from an increase in stratospheric $\mathrm{H}_{2} \mathrm{O}$. Again there is no observational information of a temporal change in the $\mathrm{D}$ content of stratospheric $\mathrm{H}_{2} \mathrm{O}$, except that it could not have been large over the duration of the ATMOS flights [Irion et al., 1996; Moyer et al., 1996]. So, of all the minor effects, at this point only the increase in stratospheric $\mathrm{H}_{2} \mathrm{O}$ makes a definite and reasonably quantifiable contribution to $\tau_{\text {HTO. It }}$ amounts to $5 \%$. Accepting 5.12 years for $\tau$, the corresponding $\tau_{\text {HTO }}$ would be 5.4 years. If we further account for the radioactive decay within the stratosphere, the removal time of HTO from the stratosphere by transport to the troposphere, $\tau_{\text {tr }}=7.7$ years (ignoring the $\mathrm{H}_{2} \mathrm{O}$ increase would yield a $\tau_{\text {tr }}=7.2$ years). We further note that this removal time is essentially the same for all altitudes, since the form of the vertical $\mathrm{T}$ profiles did not change with time. The value $\tau_{\text {tr }}$ has an error which is larger than that expected from a mere propagation of the statistical error in $\tau$ of \pm 0.18 year, since both assumptions, namely that of a cosmogenic background of zero and that of an increase of stratospheric $\mathrm{H}_{2} \mathrm{O}$ of $1 \% \mathrm{yr}^{-1}$, entail uncertainties. To account for the background we assume an error in $\tau$ of \pm 0.7 year, large enough to encompass the value of 4.6 years obtained for a forced background of $0.5 \times 10^{6} \mathrm{TU}$. To account for the uncertainty in the stratospheric $\mathrm{H}_{2} \mathrm{O}$ trend, we assume an error of $\pm 2 \%$ $\mathrm{yr}^{-1}$, to allow for the fact that there were periods when the stratospheric $\mathrm{H}_{2} \mathrm{O}$ content seemed to decrease [SPARC, 2000]. Propagating both errors, we obtain an error in $\tau_{\text {tr }}$ of \pm 2 years.

[40] The removal time of HTO from the stratosphere by transport $\tau_{\text {tr }}$ is a physical parameter that can be compared to the stratospheric residence times of other, inert tracers or to the so-called age of stratospheric air. The stratospheric residence time $\tau_{\text {res }}$ of a tracer is usually defined as the stratospheric burden of that tracer divided by its removal rate under steady state conditions. This implies a constant stratospheric source. The age $\Gamma(z)$ is usually derived from the time by which the mixing ratio in the stratosphere lags behind that in the troposphere of a tracer with a positive linear trend. It characterizes the mean time that an air parcel spent in the stratosphere since its last contact with the troposphere. In a two-dimensional (2-D) and 3-D model analysis and intercomparison, Hall and Waugh [2000] have shown that the stratospheric residence time and the age at $20 \mathrm{~km}$ altitude and $50^{\circ} \mathrm{N}$ latitude are approximately linearly related, the latter being somewhat larger than the former. Hall et al. [1999a], comparing a number of models, showed that the age varied with altitude from $\sim 2$ years at $20 \mathrm{~km}$ to at most 5 years at $40 \mathrm{~km}$ altitude for $30^{\circ} \mathrm{N}$ latitude, the conditions considered here. Ages derived empirically from measurements of the stratospheric concentrations of $\mathrm{CO}_{2}$ or $\mathrm{SF}_{6}$ are generally larger and range from $\sim 2$ years at $20 \mathrm{~km}$ up to 6 years at $40 \mathrm{~km}$ at northern midlatitudes [Schmidt and Khedim, 1991; Pollock et al., 1992; Harnisch et al., 1996; Daniel et al., 1996; Elkins et al., 1996; Strunk et al., 2000]. The observed ages increased with higher latitudes and higher altitudes.

[41] Clearly, the removal time for HTO from the stratosphere $\tau_{\text {tr }}$ derived above is significantly longer than modeled or measured ages or residence times of stratospheric air. The reason is that each of the times $\tau_{\text {tr }}, \tau_{\text {res }}$, and $\Gamma(z)$ characterizes stratospheric transport from the perspective of different boundary conditions. The time $\tau_{\text {tr }}$ considers the long-term decay after an initial pulse-type injection into the stratosphere, $\tau_{\text {res }}$ considers steady state conditions resulting from a constant source within the stratosphere, and $\Gamma(\mathrm{z})$ considers the stratospheric response to a linearly increasing mixing ratio at the lower boundary. To illustrate the possible consequences resulting from these different boundary conditions, we turn to the simplest description of stratospheric transport, namely that by one-dimensional vertical eddy diffusion with a constant eddy diffusion coefficient $K$ and a constant scale height $H$. Such a model has the advantage that it can be solved analytically for all three cases.

[42] Hall and Plumb [1994] have shown that in this case the age, $\Gamma(z)$, at altitude $z$ above the tropopause is given by

$$
\Gamma(z)=\frac{H}{K} \cdot z
$$

To compare with $\tau_{\text {tr }}$, we are interested in the age of air averaged over the full vertical extent of the stratosphere. We therefore integrate $\Gamma(z)$ over altitude weighted by the air density $\rho=\rho_{0} \cdot e^{-z / H}$

$$
\Gamma=\frac{\int_{0}^{\infty} \Gamma(z) \cdot \rho_{0} \cdot e^{-z / H} d z}{\int_{0}^{\infty} \rho_{0} \cdot e^{-z / H} d z}=\frac{H^{2}}{K} .
$$

[43] The stratospheric residence time of a tracer, $\tau_{\text {res }}=$ (stratospheric burden)/(stratospheric loss rate) is also readily calculated for this case. We consider a tracer injected at altitude $z_{I}$ above the tropopause with the rate $P$. The boundary conditions are $M(0)=0, d M(\infty) / \mathrm{dz}=0$. In steady state the mixing ratio $M$ above $z(I)$ is constant; below it is given by the constant flux

$$
F=-\rho \cdot K \cdot \frac{\partial M(z)}{\partial z}
$$

Here $F=-P$, since diffusive transport to the troposphere is the only loss. The solution for the mixing ratio $M(z)$ at height $z$ above the tropopause is given by

$$
M(z)=\frac{P \cdot H}{K \cdot \rho_{0}} \cdot\left(e^{z / H}-1\right) 0 \leq z \leq z_{I}
$$

and

$$
M(z)=\frac{P \cdot H}{K \cdot \rho_{0}} \cdot\left(e^{z_{I} / H}-1\right) z_{I} \leq z .
$$


The stratospheric burden is given by

$$
\int_{0}^{\infty} \rho(z) \cdot M(z) d z=\frac{P \cdot H \cdot z_{I}}{K}
$$

and

$$
\tau_{\text {res }}\left(z_{I}\right)=\frac{1}{P} \cdot \int_{0}^{\infty} \rho(z) \cdot M(z) d z=\frac{H \cdot z_{I}}{K}=\Gamma\left(z_{I}\right) .
$$

In the case of vertical eddy diffusion the residence time calculated for an injection at point $z_{I}$ is identical to the age, $\Gamma\left(z_{I}\right)$, at that point.

[44] The average stratospheric residence time for a tracer, whose injection is distributed with altitude as $P(z)$, is given by

$$
\begin{aligned}
\tau_{\text {res }}= & \int_{0}^{\infty} \tau_{\text {res }}\left(z_{I}\right) \cdot P\left(z_{I}\right) \cdot d z_{I} \\
& \int_{0}^{\infty} P\left(z_{I}\right) d z_{I}=\frac{H}{K} \cdot \frac{\int_{0}^{\infty} z_{I} \cdot P\left(z_{I}\right) \cdot d z_{I}}{\int_{0}^{\infty} P\left(z_{I}\right) d z_{I}},
\end{aligned}
$$

where the numerator represents the total burden and the denominator represents the total production of the tracer across the vertical extent of the stratosphere. The value of $\tau_{\text {res }}$ depends on the actual vertical distribution of the injection rate. Only when $P(z)=P_{0} \times \exp (-z / H)$, i.e., only when the altitude dependence of the injection rate equals that of the air density

$$
\tau_{\text {res }}=\mathrm{H}^{2} / \mathrm{K}=\Gamma .
$$

[45] Generally, $\tau_{\text {res }}$ will be different from $\Gamma$, the average age of air across the stratosphere: larger when the source resides in the upper stratosphere and smaller when it favors the lower stratosphere. The case given by equation (12a) would be approximated for a conservative tracer produced by the interaction of a weakly attenuated extraterrestrial radiation with air molecules.

[46] Following the decay of a pulsed injection of a tracer into the stratosphere requires a slightly larger effort than deriving $\tau_{\text {res }}$ or $\Gamma$ because it involves solving the time- and altitude-dependent partial differential equation which describes the spatial and temporal evolution of the tracer mixing ratio after the injection. In the present case of a 1-D diffusive stratosphere this equation can be solved by the separation of variables. The solutions take the form

$$
M(z, t)=\sum_{n=1}^{\infty} C_{n} \cdot F_{n}(z) \cdot e^{-t / \tau_{n}} .
$$

The $F_{n}(z)$ are the Eigenfunctions or modes [Prather, 1998] and the $1 / \tau_{n}$ are the Eigenvalues of the vertical diffusion operator

$$
\frac{\partial}{\partial z} \rho K \frac{\partial M(z, t)}{\partial z}
$$

[47] The $C_{n}$ are constants depending on the initial injection. Equation (13) shows that the general solution is a linear superposition of the modes, i.e., the modes are not coupled; once excited they decay independently of each other each with its decay time $\tau_{\mathrm{n}}$. The $F_{n}(z)$ are not necessarily analytical solutions. However, for the present case, $K=$ const and $\rho=\rho_{0} \cdot e^{-z / H}$ an analytical solution exists, if an upper boundary at $z=L$ is introduced with the condition $\partial M(L, t) / \partial \mathrm{z}=0 . M(0, t)=0$ as before. This solution was provided to us by T. Hall (private communication, 2001) and has the form

$$
M(z, t)=\sum_{n=1}^{\infty} C_{n} \cdot e^{z / 2 H} \cdot \sin \left(k_{n} \cdot z / L\right) \cdot e^{-t / \tau_{n}} .
$$

The $k_{n}$ are given by

$$
\frac{2 H}{L} \cdot k_{n}+\tan \left(k_{n}\right)=0,
$$

which ensures compliance with the upper boundary condition. They have the values $k_{1}=2.65, k_{2}=5.45, k_{3}=$ 8.39 for the lowest three modes. The Eigenvalues are

$$
1 / \tau_{n}=\frac{K}{L^{2}} \cdot k_{n}^{2}+\frac{K}{4 \cdot H^{2}} .
$$

[48] Equation (16) indicates that the decay times depend on the altitude of the upper boundary. With the mesopause as upper boundary, which appears plausible because the rocket data indicated a penetration of bomb injected HTO well into the mesosphere $L$, the altitude of the upper boundary above the tropopause equals $70 \mathrm{~km}$. With the numerical values $H=$ $7 \mathrm{~km}$ and $K=0.3 \mathrm{~m}^{2} \mathrm{~s}^{-1}$ the decay times of the lowest three modes become $\tau_{1}=16.18$ years, $\tau_{2}=9.47$ years, and $\tau_{3}=$ 5.43 years.

[49] The absolute values of these modal decay times are not realistic and are of little interest here, but their relations are. They illustrate that the higher modes die out much more quickly than the lowest mode. The higher modes represent oscillations in the mixing ratio on increasingly shorter vertical scales; they are required to describe the steep gradients present immediately after the injection. Diffusion acts more efficiently on small length scales; it therefore dampens the higher modes more rapidly, hence their shorter lifetimes. After a few decades only the lowest mode is left, and thereafter the decay of the tracer mixing ratio proceeds with a single e-fold time, just as observed for the T content. As the higher modes die out, the vertical mixing ratio profile converges to the lowest mode, which represents a smooth monotonic profile with a mixing ratio of zero at the tropopause and a maximum value at the upper boundary. This is again what we observe for the $\mathrm{T}$ profiles, if we take into account that a profile of constant $\mathrm{T}$ content means that the profile of the HTO mixing ratio increases with altitude as that of the $\mathrm{H}_{2} \mathrm{O}$ mixing ratio. So our contention is that $\tau_{\text {tr }}$, the removal time of HTO from the stratosphere, is the analogue of $\tau_{1}$; that is, it represents the decay time of the lowest mode in stratospheric transport.

[50] To compare $\tau_{1}$ with the mean stratospheric residence time or age derived above from the 1-D diffusion model we normalize it to $H^{2} / K$, with the numerical values for $H$ and $K$ used to calculate $\tau_{1}$. We obtain $\tau_{1}=3.18 \times H^{2} / K$. It is 
indeed much longer than the mean age of stratospheric air, $\Gamma=H^{2} / K$ derived above.

[51] The analogy of a 1-D model illustrates that residence time, age of stratospheric air, and the Eigentime of the lowest mode represent different, albeit related, concepts defining the temporal response of stratospheric transport. In the case of a 1-D diffusive stratosphere they lead to numerically different results. In particular, $\tau_{1}$, the analogy to our $\tau_{\text {tr }}$, is considerably longer than the mean age of stratospheric air.

[52] The question is what happens in the real 3-D world? We would like to argue that the same thing, or at least something very similar, happens. Holton [1986] has shown that a 1-D model with an appropriate $K$ realistically describes the mean vertical features of a 2-D world, which includes vertical and horizontal transport by the mean meridional circulation. Thus the concept of modes should translate at least approximately to 2-D models. More recently, Hall et al. [1999b] pointed out that the modeled spatial and temporal distribution of a conserved tracer in the stratosphere resulting from an instantaneous injection can be decomposed into 3-D modes. These represent a set of 3-D patterns in the mixing ratios and are an attribute of the equations that govern transport and therefore a fundamental property of the atmospheric motions in the model. By the same token they should exist at least as an approximation in the real world. The stratospheric profiles of the $\mathrm{T}$ content in water vapor happened to probe the lowest mode of these patterns in the stratosphere. In fact, the result of a single e-fold time is another indication that such a mode exists in the real stratosphere. The empirical Eigentime 7.7 years, belonging to the lowest 3-D mode, applies everywhere in the stratosphere. The measured profiles of the $\mathrm{T}$ content, however, describe only the vertical component of that mode at $32^{\circ} \mathrm{N}$ latitude, the latitude mainly sampled. They provide no answer about the horizontal pattern of that mode. In a sense we missed our original target, namely the determination of the stratospheric residence time of water vapor. Instead we derived a more fundamental quantity, the Eigentime of the lowest mode in the mixing ratio distribution of the stratosphere. There is one immediate implication of $\tau_{\text {tr }}$. The Eigentime of the lowest 3-D mode $\tau_{1}$ * influences the shape of the age spectrum of stratospheric air: Hall et al. [1999b] showed that the age spectrum decays exponentially towards higher ages with an e-fold time equaling $\tau_{1}{ }^{*}$, and it does so at every location in the stratosphere. With $\tau_{\text {tr }}$ we have for the first time an experimental value for that time. Hall et al. [1999b] also derived theoretical values for $\tau_{1} *$ from a number of 2-D and 3-D models. They varied between 1.4 years and 5.4 years, the majority being much smaller than the experimental value $\tau_{\mathrm{tr}}=7.7$ years. Consequently, their age spectra decay more rapidly with higher age than that based on $\tau_{\text {tr }}$, which would explain why most of the models underpredict the measured ages of stratospheric air by a factor of 2 or more. Thus $\tau_{\text {tr }}$ provides an additional constraint and useful diagnostic for stratospheric transport in 3-D chemical transport models.

\section{Conclusion}

[53] We have reanalyzed the historic measurements of the $\mathrm{T}$ content in stratospheric water vapor made at the National Center for Atmospheric Research, Boulder, Colorado, between 1975 and 1983. The reanalysis was based on the observed correlations of the $\mathrm{D}$ and $\mathrm{T}$ content and corrected for the unavoidable isotopic exchange of the sampled water vapor with water adsorbed on the inner walls of the sampling device. The resulting vertical profiles of the $\mathrm{T}$ content in $\mathrm{H}_{2} \mathrm{O}$, mainly at $32^{\circ} \mathrm{N}$ latitude, show little variation with altitude above $20 \mathrm{~km}$ but a strong decay in time. By comparing with earlier measurements of the $\mathrm{T}$ content in stratospheric water vapor from rocket samples, we could show that this decay dates back to at least 1968 and is most likely induced by the large injections of HTO from the high-yield atmospheric thermonuclear tests prior to 1963. Correcting for the radioactive decay of HTO within the stratosphere and for a temporal increase in stratospheric $\mathrm{H}_{2} \mathrm{O}$, we obtained a decay time for stratospheric HTO of $7.7 \pm 2.0$ years. It is due to transport of HTO into the troposphere and is large when compared with the age of stratospheric air at these altitudes. We argue that this HTO decay time represents the e-fold time of the longest-lived mode of a tracer distribution in the stratosphere. It presents a new aspect of stratospheric transport and offers an additional test for stratospheric transport models.

\section{Appendix A: Tables}

[54] The tables give the measured D- and T-content, corrected T-content, sample altitude, and sample volume for the balloon flights since 1979. For completeness the amount of $\mathrm{H}_{2} \mathrm{O}$ recovered and the measured mixing ratios of $\mathrm{H}_{2}$ and $\mathrm{CH}_{4}$ in the samples are also given.

Table A1. Balloon Flight 25, 2 December 1979, Ceara, Brazil, $6^{\circ} \mathrm{N}$ Latitude With Tropopause Height $16.6 \mathrm{~km}$

\begin{tabular}{|c|c|c|c|c|c|c|c|}
\hline $\begin{array}{l}\text { Altitude, } \\
\mathrm{km}\end{array}$ & $\begin{array}{c}\text { Sample Volume, } \\
\text { mL STP }\end{array}$ & $\begin{array}{c}\mathrm{H}_{2} \mathrm{O} \text { Recovered, } \\
\text { mL torr }\end{array}$ & $\begin{array}{c}\text { D Content Measured, } \\
\% \text { SMOW }\end{array}$ & $\begin{array}{c}\mathrm{T} \text { Content Measured, } \\
10^{6} \mathrm{TU}\end{array}$ & $\begin{array}{c}\mathrm{H}_{2} \text { Mix Ratio, } \\
\text { ppm }\end{array}$ & $\begin{array}{c}\mathrm{CH}_{4} \text { Mix Ratio, } \\
\text { ppm }\end{array}$ & $\begin{array}{c}\text { T Content Corrected, } \\
10^{6} \mathrm{TU}\end{array}$ \\
\hline 34.7 & 13050 & $34.5 \pm 0.6$ & -232 & $1.85 \pm 0.14$ & 0.47 & 1.06 & $5.2 \pm 0.7$ \\
\hline 33.7 & 19638 & $39.6 \pm 0.8$ & -271 & $2.52 \pm 0.39$ & & & $5.5 \pm 0.8$ \\
\hline 30.6 & 30825 & $52.4 \pm 0.5$ & -386 & $2.71 \pm 0.18$ & & & $4.5 \pm 0.7$ \\
\hline 26.4 & 30170 & $57.5 \pm 0.6$ & -389 & $2.8 \pm 0.20$ & & & $4.7 \pm 0.7$ \\
\hline 22.2 & 27630 & $44.3 \pm 0.7$ & -354 & $1.72 \pm 0.48$ & & & $4.1 \pm 0.8$ \\
\hline 19.6 & 18210 & $25.4 \pm 0.3$ & -360 & $1.22 \pm 0.28$ & & & $3.6 \pm 0.7$ \\
\hline 18.7 & 12818 & $12.9 \pm 0.4$ & -317 & $1.35 \pm 0.67$ & 0.45 & 1.63 & $4.2 \pm 1.0$ \\
\hline 17.2 & 13960 & $23.6 \pm 0.6$ & -421 & $0.77 \pm 0.38$ & 0.42 & 1.69 & $2.4 \pm 0.8$ \\
\hline 16.7 & 9425 & $17.9 \pm 0.5$ & -326 & $0.23 \pm 0.30$ & 0.44 & 1.85 & $2.8 \pm 0.8$ \\
\hline
\end{tabular}


Table A2. Balloon Flight 26, 6 May 1981, Palestine, Texas, $32^{\circ} \mathrm{N}$ Latitude With Tropopause Height $11.8 \mathrm{~km}$

Altitude, Sample Volume, $\mathrm{H}_{2} \mathrm{O}$ Recovered, D Content Measured, T Content Measured, $\mathrm{H}_{2} \mathrm{Mix} \mathrm{Ratio,} \mathrm{CH}_{4} \mathrm{Mix}_{\mathrm{Ratio}}$, T Content Corrected,

\begin{tabular}{|c|c|c|c|c|c|c|c|}
\hline $\mathrm{km}$ & $\mathrm{mL}$ STP & $\mathrm{mL}$ torr & $\%$ SMOW & $10^{6} \mathrm{TU}$ & ppm & ppm & $10^{6} \mathrm{TU}$ \\
\hline 35.2 & 15160 & $49.9 \pm 0.2$ & -324 & $1.64 \pm 0.17$ & & & $3.1 \pm 0.6$ \\
\hline 33.8 & 9380 & $37 \pm 0.2$ & -346 & $1.60 \pm 0.24$ & 0.52 & 0.86 & $3.2 \pm 0.6$ \\
\hline 31.7 & 14030 & $66.6 \pm 0.5$ & -339 & $1.65 \pm 0.10$ & 0.50 & 1.02 & $3.4 \pm 0.5$ \\
\hline 29.2 & 13530 & $38 \pm 0.4$ & -372 & $1.54 \pm 0.19$ & 0.54 & 0.96 & $3.0 \pm 0.6$ \\
\hline 27.1 & 18460 & $42.5 \pm 0.7$ & -421 & $1.82 \pm 0.18$ & & & $3.0 \pm 0.6$ \\
\hline 25.5 & 17730 & $58.8 \pm 0.1$ & -360 & $2.32 \pm 0.16$ & 0.45 & 0.45 & $4.0 \pm 0.6$ \\
\hline 24.5 & 17920 & $36.8 \pm 0.7$ & -452 & $2.06 \pm 0.25$ & & & $3.0 \pm 0.6$ \\
\hline 20.5 & 17605 & $38 \pm 0.8$ & -394 & $1.74 \pm 0.26$ & & & $3.3 \pm 0.6$ \\
\hline 16.7 & 14520 & $23.3 \pm 0.6$ & -417 & $1.39 \pm 0.32$ & 0.48 & 1.55 & $2.6 \pm 0.6$ \\
\hline
\end{tabular}

Table A3. Balloon Flight 27, 20 September 1981, Palestine, Texas, $32^{\circ} \mathrm{N}$ Latitude With Tropopause Height $12.4 \mathrm{~km}$

\begin{tabular}{|c|c|c|c|c|c|c|c|}
\hline $\begin{array}{l}\text { Altitude, } \\
\mathrm{km}\end{array}$ & $\begin{array}{c}\text { Sample Volume, } \\
\text { mL STP }\end{array}$ & $\begin{array}{c}\mathrm{H}_{2} \mathrm{O} \text { Recovered, } \\
\text { mL torr }\end{array}$ & $\begin{array}{c}\text { D Content Measured, } \\
\% \text { SMOW }\end{array}$ & $\begin{array}{c}\text { T Content Measured, } \\
10^{6} \mathrm{TU} \\
\end{array}$ & $\begin{array}{l}\mathrm{H}_{2} \text { Mix Ratio, } \\
\text { ppm }\end{array}$ & $\begin{array}{l}\mathrm{CH}_{4} \text { Mix Ratio, } \\
\text { ppm }\end{array}$ & $\begin{array}{c}\text { T Content Corrected, } \\
10^{6} \mathrm{TU} \\
\end{array}$ \\
\hline 32.9 & 26930 & $40 \pm 0.5$ & -385 & $1.88 \pm 0.57$ & 0.46 & 0.94 & $3.1 \pm 0.8$ \\
\hline 30.8 & 19850 & $47.1 \pm 0.5$ & -387 & $2.05 \pm 0.19$ & 0.47 & 1.10 & $3.3 \pm 0.5$ \\
\hline 27.6 & 18380 & $33 \pm 0.4$ & -431 & $1.98 \pm 0.27$ & 0.47 & 1.70 & $3.0 \pm 0.6$ \\
\hline 26.0 & 24040 & $36.4 \pm 0.7$ & -394 & $1.76 \pm 0.22$ & 0.47 & 1.15 & $3.1 \pm 0.5$ \\
\hline 24.5 & 32410 & $70.4 \pm 0.4$ & -489 & $2.85 \pm 0.21$ & 0.43 & 1.2 & $3.4 \pm 0.5$ \\
\hline 23.1 & 27220 & $61.8 \pm 0.7$ & -478 & $2.9 \pm 0.12$ & 0.43 & 1.26 & $3.6 \pm 0.5$ \\
\hline 21.9 & 32770 & $81.9 \pm 0.7$ & -517 & $3.06 \pm 0.09$ & 0.46 & 1.4 & $3.5 \pm 0.5$ \\
\hline 21.4 & 24250 & $50.9 \pm 0.5$ & -490 & $2.36 \pm 0.21$ & 0.46 & 1.38 & $3.0 \pm 0.5$ \\
\hline 21.1 & 25660 & $54.4 \pm 0.6$ & -459 & $2.48 \pm 0.16$ & 0.47 & 1.48 & $3.4 \pm 0.5$ \\
\hline 20.7 & 27180 & $58.3 \pm 0.6$ & -466 & $2.57 \pm 0.21$ & 0.44 & 1.48 & $3.4 \pm 0.5$ \\
\hline 20.2 & 25070 & $40 \pm 0.1$ & -444 & $2.17 \pm 0.21$ & 0.44 & 1.53 & $3.2 \pm 0.5$ \\
\hline 18.0 & 20540 & $34.9 \pm 0.3$ & -413 & $1.53 \pm 0.26$ & 0.46 & 1.54 & $2.8 \pm 0.6$ \\
\hline
\end{tabular}

Table A4. Balloon Flight 28, 15 May 1982, Palestine, Texas, $32^{\circ} \mathrm{N}$ Latitude With Tropopause Height $13.8 \mathrm{~km}$

\begin{tabular}{|c|c|c|c|c|c|c|c|}
\hline $\begin{array}{l}\text { Altitude, } \\
\mathrm{km}\end{array}$ & $\begin{array}{l}\text { Sample Volume, } \\
\text { mL STP }\end{array}$ & $\begin{array}{c}\mathrm{H}_{2} \mathrm{O} \text { Recovered, } \\
\text { mL torr }\end{array}$ & $\begin{array}{c}\text { D Content Measured, } \\
\% \text { SMOW }\end{array}$ & $\begin{array}{c}\text { T Content Measured, } \\
10^{6} \mathrm{TU} \\
\end{array}$ & $\begin{array}{c}\mathrm{H}_{2} \text { Mix Ratio, } \\
\text { ppm }\end{array}$ & $\begin{array}{c}\mathrm{CH}_{4} \text { Mix Ratio, } \\
\text { ppm }\end{array}$ & $\begin{array}{c}\text { T Content Corrected, } \\
10^{6} \mathrm{TU} \\
\end{array}$ \\
\hline 31.8 & 50464 & $69.5 \pm 0.7$ & -313 & $1.02 \pm 0.12$ & $0.42 \pm 0.1$ & $1.06 \pm 0.01$ & $2.6 \pm 0.5$ \\
\hline 31.7 & 35049 & $66.4 \pm 1.1$ & -357 & $1.01 \pm 0.13$ & $0.46 \pm 0.1$ & $0.99 \pm 0.01$ & $2.3 \pm 0.4$ \\
\hline 31.8 & 78232 & $215.2 \pm 0.5$ & -471 & $2.07 \pm 0.05$ & & & $2.6 \pm 0.4$ \\
\hline 29.8 & 43095 & $90.6 \pm 0.6$ & -429 & $1.76 \pm 0.11$ & $0.5 \pm 0.1$ & $0.95 \pm 0.01$ & $2.6 \pm 0.4$ \\
\hline 30.4 & 52841 & $164.2 \pm 0.8$ & -430 & $2.04 \pm 0.07$ & $0.37 \pm 0.1$ & $0.58 \pm 0.01$ & $2.8 \pm 0.4$ \\
\hline 29.9 & 41817 & $129.6 \pm 0.8$ & -441 & $1.88 \pm 0.07$ & $0.45 \pm 0.1$ & $0.94 \pm 0.01$ & $2.6 \pm 0.4$ \\
\hline 28.4 & 45171 & $109.5 \pm 1.1$ & -446 & $2.03 \pm 0.07$ & $0.5 \pm 0.1$ & $1.06 \pm 0.01$ & $2.8 \pm 0.4$ \\
\hline 28.3 & 13518 & $37.8 \pm 0.5$ & -256 & $1.55 \pm 0.22$ & $0.47 \pm 0.1$ & $1.02 \pm 0.01$ & $3.6 \pm 0.5$ \\
\hline 29.2 & 32493 & $178 \pm 1.5$ & -434 & $2.23 \pm 0.06$ & $0.48 \pm 0.1$ & $1.00 \pm 0.01$ & $3.0 \pm 0.4$ \\
\hline 29.2 & 32196 & $144.9 \pm 1.1$ & -375 & $1.72 \pm 0.06$ & $0.48 \pm 0.1$ & $0.99 \pm 0.01$ & $2.9 \pm 0.4$ \\
\hline 26.8 & 18268 & $78.3 \pm 0.5$ & -313 & $1.46 \pm 0.08$ & $0.49 \pm 0.1$ & $1.08 \pm 0.01$ & $3.1 \pm 0.4$ \\
\hline 24.4 & 16791 & $84.2 \pm 1.1$ & -307 & $1.19 \pm 0.10$ & $0.44 \pm 0.1$ & $1.18 \pm 0.01$ & $2.9 \pm 0.4$ \\
\hline 20.9 & 25172 & $23 \pm 1.1$ & -321 & $0.87 \pm 0.36$ & $0.48 \pm 0.1$ & $1.32 \pm 0.01$ & $2.6 \pm 0.6$ \\
\hline 20.0 & 29824 & $47.7 \pm 0.9$ & -343 & $1.28 \pm 0.15$ & $0.5 \pm 0.1$ & $1.24 \pm 0.01$ & $2.8 \pm 0.5$ \\
\hline 18.5 & 32568 & $30.1 \pm 0.9$ & -328 & $1.02 \pm 0.29$ & $0.5 \pm 0.1$ & $1.54 \pm 0.02$ & $2.7 \pm 0.5$ \\
\hline
\end{tabular}

Table A5. Balloon Flight 29, 14 October 1983, Palestine, Texas, $32^{\circ} \mathrm{N}$ Latitude With Tropopause Height $13.4 \mathrm{~km}$

\begin{tabular}{|c|c|c|c|c|c|c|c|}
\hline $\begin{array}{l}\text { Altitude, } \\
\text { km }\end{array}$ & $\begin{array}{c}\text { Sample Volume, } \\
\text { mL STP }\end{array}$ & $\begin{array}{c}\mathrm{H}_{2} \mathrm{O} \text { Recovered, } \\
\text { mL torr }\end{array}$ & $\begin{array}{c}\text { D Content Measured, } \\
\% \text { SMOW }\end{array}$ & $\begin{array}{c}\text { T Content Measured, } \\
10^{6} \mathrm{TU} \\
\end{array}$ & $\begin{array}{c}\mathrm{H}_{2} \text { Mix Ratio, } \\
\text { ppm }\end{array}$ & $\begin{array}{c}\mathrm{CH}_{4} \text { Mix Ratio, } \\
\text { ppm } \\
\end{array}$ & $\begin{array}{c}\text { T Content Corrected, } \\
10^{6} \mathrm{TU} \\
\end{array}$ \\
\hline 39.3 & 13483 & $38.6 \pm 0.2$ & -172 & $0.65 \pm 0.22$ & & & $2.3 \pm 0.4$ \\
\hline 38.6 & 10214 & $35.2 \pm 0.4$ & -187 & $0.56 \pm 0.17$ & $0.43 \pm 0.01$ & $0.79 \pm 0.00$ & $2.2 \pm 0.4$ \\
\hline 36.5 & 12263 & $34 \pm 0.3$ & -239 & $0.41 \pm 0.18$ & $0.41 \pm 0.01$ & $1.04 \pm 0.01$ & $1.8 \pm 0.4$ \\
\hline 34.9 & 12786 & $40 \pm 0.6$ & -302 & $0.57 \pm 0.19$ & $0.44 \pm 0.01$ & $1.01 \pm 0.01$ & $1.8 \pm 0.4$ \\
\hline 32.9 & 16316 & $54.5 \pm 0.2$ & -308 & $0.88 \pm 0.14$ & $0.54 \pm 0.01$ & $1.07 \pm 0.01$ & $2.1 \pm 0.4$ \\
\hline 30.0 & 17979 & $72.5 \pm 0.3$ & -293 & $0.85 \pm 0.12$ & $0.43 \pm 0.01$ & $1.03 \pm 0.01$ & $2.2 \pm 0.4$ \\
\hline 23.6 & 33359 & $105 \pm 1.0$ & -380 & $1.27 \pm 0.08$ & $0.45 \pm 0.01$ & $1.16 \pm 0.01$ & $2.2 \pm 0.3$ \\
\hline 30.3 & 36364 & $98.3 \pm 0.9$ & -257 & $1.01 \pm 0.07$ & $0.44 \pm 0.01$ & $1.15 \pm 0.01$ & $2.5 \pm 0.3$ \\
\hline 26.6 & 23385 & $55 \pm 0.5$ & -211 & $1.37 \pm 0.18$ & $0.45 \pm 0.01$ & $1.01 \pm 0.01$ & $3.2 \pm 0.4$ \\
\hline 23.6 & 30128 & $70.3 \pm 0.7$ & -355 & $1.03 \pm 0.11$ & $0.44 \pm 0.01$ & $1.18 \pm 0.01$ & $2.1 \pm 0.3$ \\
\hline 21.8 & 23921 & $38.2 \pm 0.2$ & -220 & $0.49 \pm 0.23$ & $0.44 \pm 0.01$ & $1.54 \pm 0.01$ & $2.3 \pm 0.4$ \\
\hline 20.7 & 21612 & $40.5 \pm 0.4$ & -278 & $1.26 \pm 0.22$ & $0.42 \pm 0.01$ & $1.45 \pm 0.01$ & $2.8 \pm 0.4$ \\
\hline 19.8 & 23242 & $50.6 \pm 0.5$ & -430 & $0.65 \pm 0.16$ & $0.41 \pm 0.01$ & $1.43 \pm 0.01$ & $1.4 \pm 0.4$ \\
\hline 19.0 & 23634 & $55 \pm 1.0$ & -320 & $0.36 \pm 0.16$ & $0.45 \pm 0.01$ & $1.53 \pm 0.01$ & $1.7 \pm 0.4$ \\
\hline 17.3 & 26615 & $51.9 \pm 0.5$ & -276 & $0.70 \pm 0.15$ & $0.51 \pm 0.01$ & $1.54 \pm 0.01$ & $2.2 \pm 0.4$ \\
\hline
\end{tabular}


[55] Acknowledgments. We would like to thank Tim Hall for providing the time-dependent solution of the vertical diffusion equation and Michael Prather for helpful discussions. D. H. Ehhalt gratefully acknowledges the position of affiliate scientist of the atmospheric chemistry division of NCAR.

\section{References}

Abbas, M. M., et al., Seasonal variations of water vapor in the lower stratosphere inferred from ATMOS/ATLAS-3 measurements of $\mathrm{H}_{2} \mathrm{O}$ and $\mathrm{CH}_{4}$, Geophys. Res. Lett., 23, 2401-2404, 1996.

Chang, A. Y., et al., A comparison of measurements from ATMOS and instruments aboard the ER-2 aircraft: Tracers of atmospheric transport, Geophys. Res. Lett., 23, 2389-2392, 1996.

Craig, H., and D. Lal, The production rate of natural tritium, Tellus, XIII, $85-105,1961$

Daniel, J. S., S. M. Schauffler, W. H. Pollock, S. Solomon, A. Weaver, L. E. Heidt, R. R. Garcia, and E. L. Atlas, On the age of stratospheric air and inorganic chlorine and bromine release, J. Geophys. Res., 101, 16,757$16,770,1996$.

Ehhalt, D. H., L. E. Heidt, R. H. Lueb, and E. A. Martell, Concentrations of $\mathrm{CH}_{4}, \mathrm{CO}, \mathrm{CO}_{2}, \mathrm{H}_{2}, \mathrm{H}_{2} \mathrm{O}$ and $\mathrm{N}_{2} \mathrm{O}$ in the upper stratosphere, J. Atmos. Sci., 32, 163-169, 1975.

Elkins, J. W., et al., Airborne gas chromatograph for in situ measurements of long-lived species in the upper troposphere and lower stratosphere, Geophys. Res. Lett., 23, 347-350, 1996.

Eriksson, E., An account of the major pulses of tritium and their effects in the atmosphere, Tellus, XVII, 118-130, 1965.

Hall, T. M., and R. A. Plumb, Age as a diagnostic of stratospheric transport, J. Geophys. Res., 99, 1059-1070, 1994.

Hall, T. M., D. W. Waugh, K. A. Boering, and R. A. Plumb, Evaluation of transport in stratospheric models, J. Geophys. Res., 104, 18,815-18,839 1999a.

Hall, T. H., D. J. Wuebbles, K. A. Boering, R. S. Eckman, J. Lerner, R. A. Plumb, D. H. Rind, C. P. Rinsland, D. W. Waugh, and C.-F. Wei, Transport experiments, in Models and Measurements Intercomparison II, TM1999-209554, edited by J. H. Park et al., NASA, Washington, D.C., $1999 \mathrm{~b}$.

Hall, T. M., and D. W. Waugh, Stratospheric residence time and its relationship to mean age, J. Geophys. Res., 105, 6773-6782, 2000.

Harnisch, J., R. Borchers, P. Fabian, and M. Maiss, Tropospheric trends for $\mathrm{CF}_{4}$ and $\mathrm{C}_{2} \mathrm{~F}_{6}$ since 1982 derived from $\mathrm{SF}_{6}$ dated stratospheric air, Geophys. Res. Lett., 23, 1099-1102, 1996.

Holton, J. R., A dynamically based transport parameterisation for one-dimensional photochemical models of the stratosphere, J. Geophys. Res., 91, 2681-2686, 1986.

Irion, F. W., et al., Stratopheric observations of $\mathrm{CH}_{3} \mathrm{D}$ and $\mathrm{HDO}$ from ATMOS infrared solar spectra: Enrichments of deuterium in methane and implications for HD, Geophys. Res. Lett., 23, 2381-2384, 1996.
Lal, D., and B. Peters, Cosmic ray produced isotopes and their application to problems in geophysics, Prog. Elem. Part. Cosmic Ray Phys., VI 3 74, 1962.

Lueb, R. A., D. H. Ehhalt, and L. E. Heidt, Balloon-borne low temperature air sampler, Rev. Sci. Instrum., 46, 702-705, 1975.

Masarik, J., and J. Beer, Simulation of particle fluxes and cosmogenic nuclide production in the Earth's atmosphere, J. Geophys. Res., 104, 12,099-12,111, 1999

Mason A. S., Stratospheric HTO perturbations 1980-1983, Tellus, Ser. B, $37,41-45,1985$

Mason A. S. and H. G. Östlund, Atmospheric HT and HTO, V, Distribution and large-scale circulation, in Behaviour of Tritium in the Environment, IAEA-SM-232/62, Int. At. Energy Agency, Vienna, 1979.

Mason A. S., G. Hut, and K. Telegadas, Stratospheric HTO and ${ }^{95} \mathrm{Zr}$ residence times, Tellus, 34, 369-375, 1982.

Moyer, E. J., F. W. Irion, Y. L. Yung, and M. R. Gunson, ATMOS stratospheric deuterated water and implications for troposphere-stratosphere transport, Geophys. Res. Lett., 23, 2385-2388, 1996.

Östlund, H. G., and A. S. Mason, Atmospheric tritium, prog. rep., U. S. Dep. of Energy, Washington, D.C., 1979.

Pollock, W., L. E. Heidt, R. Lueb, and D. Ehhalt, Measurement of stratospheric water vapor by cryogenic collection, J. Geophys. Res., 85, 5555$5568,1980$.

Pollock, W. H., L. E. Heidt, R. A. Lueb, J. F. Vedder, M. J. Mills, and $\mathrm{S}$. Solomon, On the age of stratospheric air and ozone depletion potentials in polar regions, J. Geophys. Res., 97, 12,993-12,999, 1992.

Prather, M. J., Timescales in atmospheric chemistry: Coupled perturbations to $\mathrm{N}_{2} \mathrm{O}$, NOy and $\mathrm{O}_{3}$, Science, 279, 1339-1341, 1998.

Randel, W. J., F. Wu, J. M. Russel III, A. Roche, and J. W. Waters, Seasonal cycles and QBO variations in stratospheric $\mathrm{CH}_{4}$ and $\mathrm{H}_{2} \mathrm{O}$ observed in UARS HALOE data, J. Atmos. Sci., 55, 163-185, 1998.

Schmidt, U., and A. Khedim, In situ measurements of carbon dioxide in the winter arctic vortex and at midlatitudes: An indicator of the "age" of stratospheric air, Geophys. Res. Lett., 18, 763-766, 1991.

Scholz, T. G., D. H. Ehhalt, L. E. Heidt, and E. A. Martell, Water vapor, molecular hydrogen, methane, and tritium concentration near the stratopause, J. Geophys. Res., 75, 3049-3054, 1970.

Stratospheric Processes and Their Role in Climate (SPARC), Assessment of upper tropospheric and stratospheric water vapor, edited by D. Kley, J. M. Russell III, and C. Philips, WCRP-113, WMO/TD 1043, SPARC rep. 2, Geneva, Switzerland, 2000.

Strunk, M., A. Engel, U. Schmidt, C. M. Volk, and T. Wetter, $\mathrm{CO}_{2}$ and $\mathrm{SF}_{6}$ as stratospheric age tracers: consistency and the effect of mesospheric $\mathrm{SF}_{6}$-loss, Geophys. Res. Lett., 27, 341-344, 2000.

D. H. Ehhalt and F. Rohrer, Forschungszentrum Jülich, Institut II: Troposphäre, Jülich, Germany. (f.rohrer@fz-juelich.de)

W. Pollock and S. Schauffler, National Center for Atmospheric Research, Boulder, Colorado, USA. (sues@ucar.edu) 